\title{
LA INTENCIÓN DE DAR MUERTE AL FETO Y SU RELEVANCIA PARA LA IMPUTACIÓN OBJETIVA Y SUBJETIVA EN EL DELITO DE ABORTO*
}

\section{MAgdalena OSSANDón Widow ${ }^{* *}$}

RESUMEN: Un aspecto más o menos controvertido en las figuras de aborto es el de la intención específica que se requiere para integrar la faz subjetiva de los tipos penales. En este trabajo se hace un análisis de los requisitos expresos exigidos en algunas figuras de aborto, esto es, que se actúe maliciosamente (art. $342 \mathrm{CP}$ ) y con abuso del oficio (art. $345 \mathrm{CP}$ ), en conjunto con lo que dispone la normativa extrapenal que puede tener incidencia en el punto, en particular, la regulación sanitaria respecto de un eventual aborto por razones terapéuticas. Se plantea, desde esta perspectiva, que esos tipos de aborto requieren que se actúe con la finalidad precisa de dar muerte del feto, excluyendo tanto el dolo eventual como el de consecuencias necesarias. En el contexto de la actividad médica, la conducta realizada con una finalidad terapéutica y que no tiene como objeto matar al feto, ni siquiera sobrepasa el marco del riesgo permitido.

PALABRAS CLAVE: Aborto - dolo directo - intención especial doctrina del doble efecto - aborto terapéutico.

\section{INTENTION TO KILL THE FETUS AND ITS RELEVANCE TO THE OBJECTIVE AND SUBJECTIVE IMPUTATION IN THE CRIME OF ABORTION}

ABSTRACT: A more or less controversial figures of abortion is the specific intention to integrate the subjective face of the criminal types. In this paper an analysis of the express requirements required on some figures of abortion, that is, to act maliciously (art. 342 PC) and abuse of office (art. 345 PC), in conjunction with the extra criminal regulations

* Trabajo redactado en el marco del proyecto de investigación Fondecyt No 1090195 "Protección penal de la vida humana: estudio dogmático y crítico", dirigido por la misma autora, en la Pontificia Universidad Católica de Valparaíso.

Fecha de recepción: 4 de agosto de 2011.

Fecha de aceptación: 11 de noviembre de 2011.

** Doctora en Derecho por la Universidad de Navarra (España). Profesora adjunta de Derecho penal de la Pontificia Universidad Católica de Valparaíso (CHILE). Correo electrónico: magdalenaossandon@yahoo.es 
which may affect the point, in particular health regulations regarding a possible abortion for therapeutic reasons. From this perspective, these types of abortion require action in order to give accurate kill to the fetus, excluding both the posible willful ignorance as the necessary consequences. In the context of medical activity, the behavior performed with a therapeutic purpose and that is not intended to kill the fetus, not even it does not go beyond the scope of allowable risk.

KEY WORDS: Abortion - willful ignorance - special intent - doctrine of double effect - therapeutic abortion.

\section{INTRODUCCIÓN}

Como en todo delito, en el aborto tienen que concurrir determinados elementos subjetivos para poder afirmar la tipicidad de la conducta. Pero esta cuestión reviste aquí características especiales en relación con la regulación extrapenal de la materia y la eventual recepción en el ámbito sanitario de doctrinas en que la intención pueda tener un valor especial. En particular, se discute hasta qué punto tiene relevancia la intención cuando estamos frente a una actividad terapéutica que termina con la muerte del feto.

Aunque el tema tiene connotaciones profundas, las aspiraciones de este trabajo son bien acotadas. No pretendemos hacer aquí un profundo análisis de filosofía moral, de constitucionalidad ni tampoco de política criminal, de lo que debería o no debería establecer nuestra legislación penal. Nuestro objetivo es fundamentalmente dogmático, de análisis del tipo penal y las normas directamente relacionadas con este, para delimitar el rol que cumple la intención en este marco.

En este sentido, además de las disposiciones que en el Código Penal consagran el delito de aborto, existen otras normas que aluden directa o indirectamente a él y que deben ser consideradas para una interpretación sistemática del tipo penal. En lo que sigue nos abocaremos al análisis de la particular intención que, según esas disposiciones, debe concurrir para que se configure este ilícito, así como al significado dogmático que se le puede atribuir a su ausencia.

\section{1) MARCO CONSTITUCIONAL}

Es de sobra conocido que nuestra Constitución Política se refiere expresamente al sujeto pasivo del delito de aborto, el no nacido, en su artículo 19 No 1 inciso segundo. Luego de asegurar a todas las personas el derecho a la vida y a la integridad física y psíquica, dicha disposición agrega que la ley protege la vida del que está por nacer. 
Esta especial mención que se hace del que está por nacer, lejos de establecer claridad sobre su estatuto normativo, ha sido objeto de diversas interpretaciones.

Mayoritariamente la doctrina chilena considera que el que está por nacer es persona, con igual dignidad y derechos que las demás personas; y que tiene, por tanto, derecho a la vida al igual que los seres humanos nacidos ${ }^{1}$. Pero aceptada esa premisa fundamental, existe divergencia en

1 Cea Egaña, José Luis (2004). Derecho constitucional chileno, II, Santiago: Ediciones Universidad Católica de Chile, 2004, pp. 47-93 y ss.; Corral Talciani, Hernán (2005). "El concepto jurídico de persona y su relevancia para la protección del derecho a la vida", Ius et Praxis, U. de Talca, Año 11, No 1, pp. 44-45; Diez Urzúa, Sergio (1999). Personas y valores. Su protección constitucional, Santiago: Edit. Jurídica de Chile, p. 126; Evans DE LA Cuadra, Enrique (2004). Los Derechos Constitucionales, t. I, $3^{\text {a }}$ ed., Santiago: Edit. Jurídica de Chile, p. 113; Evans Espiñeira, Eugenio (2000). Relación de la Constitución Politica de 1980, Santiago: ConoSur, p. 48; Fermandois Vöhringer, Arturo (2004). "La píldora del día después: aspectos normativos", en Estudios Públicos No 95, pp. 96 y 113; FuenZalida Zuñiga, Carmen Gloria (1998). "Protección jurídica del embrión en la legislación chilena", Revista Chilena de Derecho, PUC, vol. 25, No 4, pp. 834-837; Lyon Puelma, Alberto (2007). Persona naturales, $3^{a}$ ed., Santiago: Universidad Católica de Chile, pp. 45, 94 y

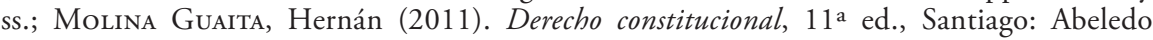
Perrot, pp. 202-204; Nogueira Alcalá, Humberto (1997). "El derecho a la vida en el ordenamiento jurídico chileno", Gaceta Jurídica, No 207, p. 9; Nogueira Alcalá, Humberto (2007). Derechos fundamentales y garantías constitucionales, t. I, Santiago: Librotecnia, p. 313; NúŃEz LeIva, José Ignacio (2010). "Estatuto constitucional del embrión humano", Hemiciclo. Revista de Estudios Parlamentarios, Academia Parlamentaria de la Cámara de Diputados, No 2, pp. 79-83; Núñez Poblete, Manuel Antonio (1998). "El derecho a la vida o el deber de respetar la vida”, en García-Huidobro, J. / Martínez Estay, I. / Núñez Poblete, M.: Lecciones de Derechos Humanos, Valparaíso: Edeval, pp. 50-51, 57-58; РRecht Pizarro, Jorge E. (1992). "Consideraciones ético-jurídicas sobre el aborto terapéutico", p. 509 y ss.; Rozas Vial, Fernando (1989). "Problemas jurídicos y morales que plantean la inseminación artificial y la fecundación in vitro", pp. 725 y ss.; Rodríguez Collao, Luis (1992). "El delito de aborto frente a la Constitución de 1980", Revista de Derecho, PUCV, XIV, p. 380; Silva MacIver, Jaime (1995). "El nasciturus y el derecho a la vida", Revista de Derecho Público, U. Chile, No 57/58, p. 193; Sото KLoss, Eduardo (1991). "La noción de persona en la Constitución: a propósito del que está por nacer", en Revista de Derecho Público, U. Chile, No 50, pp. 139-141; Ugarte Godoy, José Joaquín (2006). "El derecho a la vida y la Constitución", Revista Chilena de Derecho, PUC, vol. 33, No 3, pp. 522-523; Varela del Solar, Jorge Luis (1990). "Derechos humanos y aborto", Revista de Derecho Público, U. Chile, No 47/48, p. 197; Verdugo, M. / Pfeffer, E. / Nogueira, H. (1994). Derecho constitucional, I, 2a ed., p. 199; Vivanco Martínez, Ángela (2001). "El derecho a la vida y la discusión acerca del concepto de persona humana en el ámbito constitucional", Revista Chilena de Derecho, vol. 28, No 2, p. 478, y Zapata Larraín, Patricio (1988). "Persona y embrión humano. Nuevos problemas legales y su solución en el derecho chileno", Revista Chilena de Derecho, vol. 15, pp. 382-383. Es diferente la postura de FigueroA YÁÑEz, Gonzalo (2001). Derecho civil de la persona: del genoma al nacimiento, Santiago: Edit. Jurídica de Chile, pp. 143 y 145, pues entiende que el nasciturus es sujeto de derechos, titular del derecho a la vida, pero solo desde su implantación en el útero (antes de eso puede ser considerado una cosa, homologándose a su status aunque con restricciones). Pese a que técnicamente todavía no es una persona (advierte también que "es en verdad persona aunque el ordenamiento jurídico le niegue tal carácter", p. 150). A la doctrina se añade, también, la opinión del constituyente por Ley $\mathrm{N}^{\circ} 19.611$, publicada en el Diario Oficial de 16 de junio de 1999. Durante el segundo trámite de esa reforma constitucional, verificado en el Senado, 
cuanto al alcance de ese derecho, pues para algunos no solo sería un derecho constitucionalmente reconocido, sino que además tendría la particularidad de poseer un carácter absoluto; mientras que otros admiten que la distinción que consagra el artículo 19 No 1 de la Constitución Política entre nacidos y no nacidos permite una diversidad en el tratamiento y en las implicancias del derecho de estos últimos. En particular, el derecho a la vida del nasciturus admitiría una regulación más flexible, pudiendo el legislador establecer excepciones en su protección, por ejemplo, por razones terapéuticas.

Pero esta misma regulación ha servido también para negar que el nasciturus tenga un derecho constitucional a la vida, considerando que al que está por nacer únicamente se le garantizaría la protección legal de su $v_{i d a}{ }^{2}$; es decir, que solo podría considerársele un objeto que merece especial protección legal, pero no un sujeto de derechos.

Se trata de una discusión fundamental y que condiciona todo el debate sobre el aborto $^{3}$, pero que excede el ámbito de lo que se pretende

se aprobó dejar constancia de que: "El nasciturus, desde la concepción, es persona en el sentido constitucional del término, y por ende es titular del derecho a la vida". Por último, es también la opinión del Tribunal Constitucional, en sentencia Rol 740-07, de 18 de abril de 2008, considerando quincuagésimo cuarto.

2 Bascuñán Rodríguez, Antonio (2004). "La píldora del día después ante la Jurisprudencia”, Estudios Públicos N 95, pp. 54 y ss.; Bordalí Salamanca, Andrés / Zúñiga Añazco, Yanira (2009). "Análisis del fallo del Tribunal Constitucional sobre la píldora del día después", Anuario de Derechos Humanos, No 5, p. 177; Figueroa García-Huidobro, Rodolfo (2007). "Concepto de persona, titularidad del derecho a la vida y aborto", Revista de Derecho, Universidad Austral de Chile, vol. XX, No 2, pp. 115 y ss.; Gómez Bernales, Gastón (2005). Derechos fundamentales y recurso de protección, Santiago: Ediciones Universidad Diego Portales, p. 310; y Mayer Lux, Laura (2011). "La vida del que está por nacer como objeto de protección penal”, en Revista de Derechos Fundamentales, Universidad Viña del Mar, No 5, p. 69. Es también la línea de la doctrina penal, así Etcheberry, Alfredo (1997). Derecho Penal. Parte Especial, t. III, $3^{a}$ ed., Santiago: Edit. Jurídica de Chile, p. 92 y Garrido Montr, Mario (2007). Derecho penal. Parte Especial, t. III, $3^{a}$ ed., Santiago: Edit. Jurídica de Chile, p. 25. También, aunque en sentido crítico, Guzmán Brito, Alejandro (2001). El Derecho privado constitucional de Chile, Valparaíso: Ediciones Universitarias de Valparaíso, pp. 92 y 192 y Mohor Abuauad, Salvador (1988). "Consideraciones jurídicas y metajurídicas en torno a una eventual despenalización del aborto en Chile a la luz de la nueva Constitución”, Revista de Legislación y Documentación en Derecho, BCN, Año X, No 1, p. 44; Aldunate Lizana, Eduardo (2008). Derechos fundamentales, Santiago: LegalPublishing, p. 150, considera que no puede afirmarse la calidad de persona desde el momento de la concepción, por lo que entiende que el que está por nacer sería "solo titular del derecho de protección previsto por esta disposición [art. 19 No 1 i. II]" (el destacado es nuestro, pues resulta paradójico que el nasciturus sea considerado titular de un derecho si carece de personalidad).

3 Aunque algunos consideren que no es más que una estrategia argumental, que se limita a concentrar la discusión en "un debate que es circular y que no es decisivo para el tratamiento de los problemas prácticos involucrados", Bascuñán Rodríguez, Antonio (2004). "La licitud del aborto consentido en el Derecho chileno", Derecho y Humanidades, U. Chile, No 10, p. 158, en la línea de los planteamientos de Thomson, Judith Jarvis (1983). "Una defensa del aborto", en Finnis, John et al.: Debate sobre el aborto. Cinco ensayos de filosofía moral, Madrid: Cátedra, pp. 9-32. Sin embargo, la importancia de esta discusión se advier- 
con este trabajo. Para lo que aquí interesa nos basta con afirmar que existe, al menos, un reconocimiento expreso de la necesidad de proteger la vida del no nacido, la que en el ámbito penal se traduce en la tipificación del delito de aborto.

\section{2) Código Penal}

El Código Penal tipifica el delito de aborto en el Libro II, Título VII, artículos 342 a 345, distinguiendo según el sujeto activo que realice la conducta. Aquí nos centraremos en los artículos 342 y 345, específicamente, en cuanto ellos son los que deben traerse a colación cuando un médico se enfrenta a una situación de término del embarazo por razones terapéuticas.

\section{(2.1) Figura DEL arTíCulo 342 CP. AlCANCE DE LA EXPRESIÓN "MALICIOSAMENTE"}

A diferencia de lo que paulatinamente ha ocurrido en muchos otros cuerpos penales, nuestro Código no contempla ninguna disposición que describa en forma explícita alguna situación en que el aborto no resulte punible, ni siquiera por razones terapéuticas.

Sin embargo, dicha regulación contiene una expresión cuyo sentido original era, precisamente, reconocer que el aborto podía ser lícito en ciertos casos. El artículo $342 \mathrm{CP}$ exige que el aborto se haya causado maliciosamente. En principio, el texto sometido a consideración de la Comisión hacía referencia, siguiendo a su modelo español, a que la conducta se hubiere realizado "de propósito". Esta primera expresión aludía claramente

te claramente en la opinión de autores a los que no se les puede imputar el recurso a una "estrategia argumental". Así Dworkin, Ronald (1994). El dominio de la vida: una discusión acerca del aborto, la eutanasia y la libertad individual (trad. Caracciolo / Ferreres), Barcelona: Ariel, aunque desecha la cuestión de la personalidad en razón de su ambigüedad, p. 34, luego es muy enfático para concluir que si el feto fuera una persona "constitucional" se acabaría la discusión, debería ser protegido igual que las demás personas, pp. 146-147; y Jаковs, Günther (2000). “Existe un aborto lícito de personas?” (trad. González Rivero), Revista del Poder Judicial 60, pp. 159-168, concluye que solo si el feto no es considerado persona puede resultar justificado el aborto en ciertas hipótesis. Por lo demás, "la propuesta de excluir el problema de la calificación de la persona del debate sobre la protección jurídica de la vida, tiene como resultado la retirada del orden jurídico de la cobertura de tutela de ciertos segmentos de la vida humana", Corral TALCiani (2005) 49. Reducida a la categoría de bien, cuando esa vida se opone al ejercicio de un derecho fundamental de un individuo que sí es reconocido como persona, la decisión viene ya resuelta a favor del derecho. Aunque no lo considere "decisivo", es obvio que el propio Bascuñán habría llegado a conclusiones diversas en relación con las indicaciones que permitirían el aborto, si al ponderar los intereses involucrados, en un lado de la balanza tuviera un derecho a la vida y no un mero interés en protegerla. 
a la intencionalidad del autor. Pero fue sustituida por la Comisión Redactora con la finalidad de evitar el castigo de personas que procedían de buena fe, aunque de propósito. La consideración de que se dejó constancia en actas para hacer la modificación no puede ser más explícita al respecto: "la expresión de propósito pudiera aplicarse a muchas personas que de buena fé, proceden, por ejemplo, el médico que necesita causar el aborto i da remedios con el fin de procurarlo para salvar la vida de una enferma en peligro" 4 .

Pero frente a este claro argumento histórico de interpretación surgen otros en sentido diverso, de tal modo que el significado de la expresión maliciosamente resulta controvertido y se la ha considerado también como una referencia a la intención del sujeto que realiza la conducta. Las funciones que se le han asignado son las siguientes:

\section{(2.1.1) Referencia directa a la antijuridicidad}

Apoyándose en la opinión de la Comisión Redactora, la palabra maliciosamente ha sido interpretada como una referencia expresa a la antijuridicidad de la conducta ${ }^{5}$, que dejaría fuera del ámbito típico todos los casos de aborto en que concurra una causa de justificación.

En consecuencia, ella solo tendría sentido si efectivamente existen situaciones justificadas respecto del aborto y, en todo caso, sería una mención meramente recordatoria pero sin una función normativa especial.

\section{(2.1.2) Alusión a un error de prohibición}

En estricto rigor, la expresión empleada posee un carácter subjetivo, pues exigiría solo que quien realice un aborto lo haga con conocimiento de la antijuridicidad de su comportamiento. Por lo tanto, no serviría para excluir del ámbito típico el actuar objetivamente justificado, sino la conducta de una persona -el médico, por ejemplo- que actúe con el convencimiento de que se encuentra justificada para hacerlo. En teoría, esa representación subjetiva podría ser correcta, cuando efectivamente concurre una causa de justificación, pero también podría ser equivocada, cuando no existe la causa de justificación que se estimaba concurrente, esta no tiene el alcance que se le asigna, o se yerra sobre la concurrencia de sus presupuestos fácticos ${ }^{6}$. La disposición aludiría a estos casos, per-

Sesión 160, de 25 de junio de 1873. La sustitución se llevó a cabo por indicación del comisionado Gandarillas.

5 Así lo entienden Araya Rivera (1963) 53; Etcheberry (1997) 97 y 107, y Schepeler RAVEAU (1967) 50.

6 Se excluye el error de prohibición referido a la existencia en abstracto de la prohibición, la que resulta improcedente puesto que la referencia está inserta, precisamente, en la norma que tipifica el aborto como delito. 
mitiendo invocar un error de prohibición a quien se encontrare en esa situación ${ }^{7}$.

Podríamos, por lo tanto, estar convencidos de que no existen abortos lícitos y, aún así, dar sentido a la expresión maliciosamente como una consagración expresa del error de prohibición referido a la posibilidad de justificación. En otras palabras, la expresión legal aludiría a una causal de exculpación que no supone, necesariamente, que existan causas de justificación aplicables al delito en cuestión.

\section{(2.1.3) Referencia objetiva indirecta a la antijuridicidad}

A pesar de la posibilidad recién expuesta, es evidente que en las consideraciones de la Comisión Redactora, tanto como en la doctrina penal y en la ética médica hasta principios del siglo XX, subyace la idea de que la justificación sí era posible; en casos excepcionales el aborto estaría permitido ${ }^{8}$. En la actualidad, por su parte, también se ha propuesto una interpretación constitucional que llevaría a admitir la justificación del aborto consentido, tanto al configurarse eventuales hipótesis de estado de necesidad defensivo como en situaciones excepcionales de inexigibilidad? .

Admitiendo que existan supuestos justificados de aborto se le asigna una función objetiva indirecta a la expresión legal, por tratarse de una "referencia subjetiva a un supuesto objetivo de exclusión de la ilicitud del aborto" 10 .

7 Permitirlo de modo expreso resultaba especialmente relevante hasta hace poco tiempo, cuando ni la doctrina ni la jurisprudencia conferían valor excusante al desconocimiento de la ilicitud, en virtud de la presunción de conocimiento de la ley consagrada en el art. 8 CC; sobre esto CURY URzÚA, Enrique (2008). "El estado actual de la doctrina y jurisprudencia nacionales en torno a los problemas del error de prohibición”, VV.AA: Delito, pena y proceso. Libro homenaje a la memoria del profesor Tito Solari Peralta, Santiago: Edit. Jurídica de Chile, pp. 238.

8 Véase la bibliografía citada por BAscuñán Rodríguez (2004) 145 y 146.

9 Es la propuesta central de BASCuñ́́N Rodríguez (2004) 172-179; recogida también por Horvitz Lennon, María Inés / Soto Piñeiro, Miguel (2007). "Consideraciones críticas sobre la regulación del delito de aborto en el anteproyecto de nuevo Código Penal elaborado por el foro del Ministerio de Justicia”, Revista de Estudios de la Justicia, U. Chile, No 9, p. 88.

10 Bascuñán Rodríguez (2004) 146 (destacado en el original), si bien lo plantea en el contexto de la regulación previa a la dictación del Código Sanitario, luego afirma que esta tesis recobra su aplicabilidad en función de su propuesta de sustituir la referencia a la lex artis por la referencia al orden constitucional, que permitiría justificar ciertos casos de aborto (p. 181). También Amunátegui Stewart, Felipe (1961). "Maliciosamente" y "A sabiendas" en el Código Penal Chileno, Santiago: Edit. Jurídica de Chile, p. 47, confiere a la expresión un sentido objetivo y subjetivo, y no meramente subjetivo; el delito supone una acción objetivamente contraria al derecho realizada con conciencia clara de esa contradicción. 


\section{(2.2) RESTRICCIÓN AL DOLO DIRECTO}

Cualquiera de las posiciones antes descritas supone que la voz maliciosamente carecería de significado a nivel de dolo. Aunque la figura más grave del artículo 342 (aborto con violencia) requiere dolo directo, esto sería así no en virtud de la expresión maliciosamente, sino por comparación con la figura del artículo 343 que también contiene una hipótesis de aborto violento, en la que se incluyen los supuestos de dolo eventual ${ }^{11}$. Las restantes figuras del artículo 342 ( $\mathrm{N}^{\text {os }} 2$ y 3) podrían cometerse con dolo directo o eventual.

De aquí surge uno de los inconvenientes que ha llevado al abandono de estas opciones interpretativas. Porque seguir cualquiera de ellas implicaría castigar con menos pena el aborto con violencia cometido con dolo eventual (con presidio menor en sus grados mínimo a medio, de acuerdo al artículo 343), que el aborto cometido con dolo eventual sin violencia (al que le corresponde la pena de presidio menor en su grado máximo según el artículo 342 № 2 y presidio menor en su grado medio, si corresponde al No 3 del mismo artículo).

Además, entendida como referencia a la antijuridicidad sería una expresión inútil, toda vez que el artículo 10 No $10 \mathrm{CP}$ contempla una causal de justificación genérica -cumplimiento de un deber y ejercicio legítimo de un derecho- que serviría para abarcar las situaciones de justificación a las que se pretende aludir ${ }^{12}$.

La doctrina mayoritaria ${ }^{13}$, en consecuencia y tal como ocurre en otros casos en que el Código recurre al empleo de menciones subjetivas, asigna a la palabra maliciosamente el sentido de limitar el tipo al dolo

11 Etcheberry (1997) 98. Así también se entiende en Argentina, en que no existe una exigencia subjetiva en la hipótesis principal, pero la interpretación sistemática en relación con otra disposición (equivalente a nuestro art. 343) lleva a concluir que en el primer caso se exige dolo directo, por todos, Soler, Sebastián (1978). Derecho penal argentino, III, Buenos Aires: Tea, p. 114

12 Amunátegui Stewart (1961) 55.

13 Bullemore, V. / Mackinnon, J. (2007). Curso de Derecho penal. Parte especial, t. III, 2a ed., Santiago: LexisNexis, p. 43; Garrido Montt, Mario (2007). Derecho penal. Parte Especial, t. III, 3a ed., Santiago: Edit. Jurídica de Chile, p. 107; Oxman Vilches, Nicolás (2004). "Las figuras penales del delito de aborto", Revista de Derecho, U. Central, No 6, p. 245; Politoff, Sergio / Grisolía, Francisco / Bustos, Juan (2006). Derecho Penal Chileno. Parte Especial, $2^{a}$ ed., Santiago: Editorial Jurídica Congreso, p. 220; y Politoff, S. 1 Matus, J.P. / Ramírez, C. (2011). Lecciones de Derecho penal chileno. Parte Especial, 2a ed., Santiago: Edit. Jurídica de Chile, reimpresión, p. 98. También podemos incluir en este grupo a Labatut Glena, Gustavo (2007). Derecho Penal, t. II, 7a ed., Santiago: Edit. Jurídica de Chile, reimpresión, p. 129, quien, aunque inicialmente asigna a la expresión el objeto de establecer un requisito de antijuridicidad (p. 127), luego la interpreta como exigencia de dolo especifico, entendiendo que tras esa terminología propia de su tiempo, en el fondo propone una restricción equivalente a la que sostiene la doctrina mayoritaria actual. Similar Cousiño MacIver, Luis (1949). Manual de medicina legal, I, Santiago: Edit. Jurídica de Chile, p. 122. 
directo. De este modo, no solo la primera sino que las tres figuras del artículo 342 requerirían esa forma de dolo.

Ahora bien, cabe advertir que la restricción al dolo directo no puede derivar del mero hecho de que el tipo contenga una alusión subjetiva. Pese a que mayoritariamente expresiones como estas -sean exigencias subjetivas de conocimiento: "conociendo", "con conocimiento de causa", "a sabiendas", "constándole", etc.; o de voluntad: "maliciosamente", "de propósito", etc.- son interpretadas de ese modo, ${ }^{14}$ lo cierto es que una conclusión así debe depender tanto de la clase de expresión de que se trate como, especialmente, de un análisis del sentido de la norma ${ }^{15}$.

En este caso, la particular expresión que se emplea -maliciosamente- pone un énfasis en la voluntariedad de la conducta que ha sido considerado semánticamente incompatible con la idea de aceptar o resignarse a un resultado representado como posible, que es lo propio del dolo eventual ${ }^{16}$. Aunque el sentido de la norma no ofrece mayores razones que avalen esta posición, pues bien podría cometerse el delito con cualquier clase de dolo, bastaría el argumento gramatical y el sistemático (por la re-

14 En este sentido, aunque lo admite solo como una posibilidad, sin pretender asignarle validez general, Cousiño MacIver, Luis (1975). Derecho Penal chileno, I, Santiago: Edit. Jurídica de Chile, pp. 769 y ss.; y Politoff, S. / Matus, J. P. / Ramírez, M. C. (2011) 280. En sentido crítico, Hernández Basualto, Héctor (2004). El delito de lavado de dinero, Informe en Derecho para la Unidad Especializada de Lavado de Dinero y Delitos Económicos de la Fiscalía Nacional del Ministerio Público, p. 19. Disponible en http://www.ministeriopublico.cl/RepositorioMinpu/Archivos/minpu/Informes\%20en\%20derecho/HECTOR\%20 HERNÁNDEZ\%20lavado.doc, quien atribuye esta clase de razonamiento a "una cierta inercia frente a conclusiones extraídas de giros azarosos del texto legal, postuladas pero nunca debidamente fundadas". Ciertamente, la posibilidad de interpretar toda alusión subjetiva como una restricción a los supuestos de dolo directo puede controvertirse por diversos argumentos: (i) históricos, pues al incorporarse muchas de esas expresiones en el Código Penal el dolo eventual era desconocido para nuestro legislador (desde este punto de vista, entonces, resulta más lógico atribuirles el significado de dejar sin efecto la presunción de voluntariedad del art. $1^{\circ} \mathrm{CP}$, como sucedía en el derecho español, o para insistir en el carácter doloso de la conducta, como solía hacer el Código belga. Así lo advierte Amunátegui (1961) pp. 38 y ss.); (ii) sistemáticos, porque es fácil advertir que estas expresiones han sido empleadas de modo asistemático, sin un objetivo bien delimitado $\mathrm{y}$, en no pocas ocasiones, sin reparar en su significado y alcance (como denuncia Novoa Monreal, Eduardo (2005). Curso de Derecho penal chileno. Parte general, I, $3^{a}$ ed., Santiago: Edit. Jurídica de Chile, reimpr., p. 502), y (iii) de derecho comparado, en el que suele existir gran controversia sobre el significado de expresiones de esta clase.

15 Por todos, Martínez-Buján Pérez, Carlos (2007). Derecho penal económico y de la empresa. Parte general, $2^{\text {a }}$ ed., Valencia: Tirant lo Blanch, pp. 376-377, analiza varios ejemplos con locuciones como "a sabiendas", "dolosamente" e "intencionalmente". También RAGUÉs I VAlLÈs, Ramón (2007). La ignorancia deliberada en Derecho penal, Barcelona: Atelier, p. 105 , considera que las notables discrepancias acerca de si estas previsiones legales excluyen o no la posibilidad de aplicar el dolo eventual se debe a que su presencia no se explica por una decisión político-criminal consciente, sino por una serie de casualidades históricas o legislativas, y porque según como se interpreten podrían provocar lagunas de punibilidad no justificadas.

16 Politoff / Grisolía / Bustos (2006) 220. 
lación con la disposición del artículo 343 que ya hemos comentado), para excluir del ámbito de aplicación del artículo 342 las hipótesis de aborto cometido con dolo eventual.

\section{(2.3) EXIGENCIA DE LA INTENCIÓN DE MATAR AL FETO (RESTRICCIÓN AL DOLO DIRECTO DE PRIMER GRADO)}

Hasta aquí hemos presentado esta disquisición conforme a las teorías tradicionales sobre el concepto de dolo y su tripartición. Pero cabe hacerse cargo de una visión normativa del dolo, que nos arrojará nuevas luces para interpretar esta expresión.

Quienes adoptan un concepto normativo de dolo le asignan, generalmente, un contenido meramente cognitivo. Desde este punto de vista, entonces, basta con el conocimiento o, mejor, con la posibilidad de atribuir un determinado conocimiento, para imputar a título de dolo ${ }^{17}$. No cabe hacer una distinción entre dolo directo, indirecto o eventual, pues una particular intención o la certeza sobre la producción de un resultado no son elementos del dolo; solo pueden ser considerados a nivel de culpabilidad.

En consecuencia, el dolo propio del delito de aborto se refiere, en general, al conocimiento del estado de gravidez de la embarazada y del poder abortivo del medio empleado ${ }^{18}$. Si puede atribuirse dicho conocimiento, se podrá imputar un aborto a título doloso.

La voz maliciosamente en el delito contemplado en el artículo 342 no podría, por ende, estar referida al dolo, pues nada añade en el ámbito cognitivo. Más bien, ella exigiría una voluntad especial para poder aplicar esta figura. Dado el carácter preeminentemente volitivo de la expresión, el objeto sobre el que recae y su relación con el artículo 343, la malicia puede concebirse como una intención especial en el actuar, la que en este caso no estaría referida a otra cosa que a causar la muerte del feto; es decir, el tipo requeriría que este hubiere sido el particular propósito o finalidad que motivó el actuar del sujeto ${ }^{19}$.

Hasta aquí parece no haber ninguna diferencia práctica con la interpretación tradicional que entiende esta alusión como una restricción al dolo directo. Salvo en un aspecto: el dolo indirecto o de consecuencias necesarias. Porque desde la perspectiva tradicional suele afirmarse que esta

17 Sobre el concepto cognitivo normativo de dolo, véase, especialmente, García Cavero, Percy (2008). Lecciones de Derecho penal, Parte General, Lima: Grijley, p. 399 y Ragués I VALLÈs, Ramón (1999). El dolo y su prueba en el proceso penal, Barcelona: J. M. Bosch Editor, pp. 86-87.

18 Aunque desde una perspectiva diferente, así lo entiende Labatut (2007) 127.

19 Ha sido interpretado como exigencia de una finalidad o propósito específico, por PARAdA GuZMÁn (1963) 42. 
clase de dolo se asimila al dolo directo y recibe su mismo tratamiento. De este modo, los tipos penales que exigen dolo directo estarían excluyendo solo el dolo eventual, no así el indirecto, aunque es una conclusión que no siempre resulta clara, explícita ni, menos, positivamente justificada ${ }^{20}$.

En cambio, si se considera que la exigencia especial que contempla el tipo del artículo 342 es de carácter netamente volitivo, resulta patente que la situación conocida como dolo indirecto o de consecuencias necesarias no puede ser asimilada, sin más, a un actuar en que se requiere una voluntad dirigida a un objetivo preciso. El dolo indirecto supone conocimiento cierto respecto de la producción del resultado, pero nada dice en cuanto a la intención o propósito del sujeto, que puede ser cualquiera. Y aunque se afirme que el hecho de actuar conociendo con seguridad que se realizará el tipo implica querer este -pese a que eso no sea buscado y aparezca, incluso, como desagradable para el autor-, esa supuesta voluntad está lejos de la intención o propósito específico de matar al feto, que sería lo exigido con la expresión maliciosamente.

Esto significa, en suma, que para aplicar el tipo del artículo 342 se requiere una actuación dolosa, esto es, realizada con conocimiento del estado de gravidez de la embarazada y del poder abortivo del medio empleado y, además, que el sujeto hubiere actuado con la finalidad precisa de matar al feto. Dicho en términos de la teoría tradicional de dolo: quedarían excluidos tanto el dolo eventual como el indirecto o de consecuencias necesarias.

Esta interpretación cuenta con un sólido argumento sistemático, en virtud de las expresiones que, a su vez, se emplean en el artículo 343 CP. En esta disposición se alude a una actuación aun cuando no haya existido el propósito de causar un aborto, la que unánimemente es traducida como siempre que no haya existido ese propósito ${ }^{21}$. Así, queda clara la delimitación con la figura anterior: en el artículo 342 se incluyen solo los abortos realizados con el propósito o la intención deliberada de matar al feto, en el artículo 343 todos los demás, en que no se actúa con ese propósito, es decir, aquellos en que la muerte del feto se hubiere representado como una consecuencia segura del actuar, como un resultado posible o, incluso, aunque el autor no se lo hubiere representado pero fuere previsible.

20 Respecto del art. 342 CP, así se pronuncian, expresamente, Politoff / Grisolía / Bustos (2006) 220, pero sin dar razones de ello. Otros, en cambio, se limitan a decir que la expresión restringe el tipo subjetivo al dolo directo, sin especificar si al de primer o segundo grado; así Bullemore / Mackinnon (2007) 43; Garrido Montt (2007) 107 y Politoff / Matus / Ramírez (2011) 98. Entre ellos, Garrido Montt indica solo que resulta excluido el dolo eventual, por lo que parece aceptar el dolo de consecuencias necesarias, a pesar de que en la parte general había dicho que el legislador exigiría dolo directo de primer grado -y solo esa clase de dolo, podríamos añadir- al emplear términos como maliciosamente, poniendo como ejemplo el mismo art. 342. Garrido Montt (2007) 101.

$21 \quad$ Así Labatut (2007) 129. 
Ahora bien, el problema de interpretar la expresión contenida en el artículo $342 \mathrm{CP}$ como una restricción al dolo directo y, más aún, al dolo directo de primer grado, es que implica dejar impunes los supuestos no violentos cometidos con dolo eventual o, incluso, con dolo indirecto; pero el tenor literal de las fórmulas empleadas por el legislador impediría sancionarlos sin atentar contra el principio de legalidad.

\section{(2.4) Figura DEL ARTículo 345 CP. ObRaR “ABUSANDO DE SU OFICIO”}

Además de lo que dispone el artículo $342 \mathrm{CP}$, la legislación penal se refiere en particular a la actuación de los profesionales de la salud, que son precisamente quienes pueden actuar invocando razones terapéuticas. El artículo 345 sanciona de modo agravado el aborto cuando es cometido por un facultativo que obre abusando de su oficio.

En general se acepta que esta referencia alude a que el facultativo actúe en su calidad de tal, ejerciendo la actividad que le es inherente en su condición de profesional de la salud ${ }^{22}$.

Además de lo anterior, algunos entienden que el facultativo abusa siempre que sobrepase los límites que le fija la lex artis medica, pues de lo contrario su conducta estaría justificada ${ }^{23}$. Ahora bien, esta interpretación presupone que existan supuestos de aborto justificados por el legítimo ejercicio de la profesión de médico, fuera de los cuales existiría el abuso al que se refiere la disposición. Desde esta perspectiva, nuevamente, la mención resultaría superflua.

Otros adoptan una posición más restrictiva, en atención al efecto agravatorio que importa el que la conducta sea subsumible en el artículo 345 y no en alguna de las hipótesis del artículo 342. Así, consideran que no habría abuso, aun fuera de los casos que el aborto pudiera estar justificado de conformidad con la lex artis, mientras se actúe por una necesidad terapéutica, por consideraciones humanitarias y altruistas. En otras palabras, existiría abuso solo cuando el facultativo hubiere actuado motivado por fines diversos a los propósitos estrictamente terapéuticos que le son exigibles $^{24}$.

Tal vez por centrar la atención en este debate, lo cierto es que no se encuentran mayores comentarios sobre la faz subjetiva del tipo descrito en el artículo 345 CP. Con todo, la exigencia de una actuación abusi$v a$ bien puede vincularse con la exclusión del dolo eventual ${ }^{25}$, tal como

Confróntese Etcheberry (1997); Garrido Montt (2007) 116.

Etcheberry (1997) 104 y Garrido Montt (2007) 116.

En este sentido Araya Rivera (1963) 57 y Politoff / Grisolía / Bustos (2006) 244. De acuerdo con ellos se han pronunciado Bullemore / Mackinnon (2007) 47; Politoff / Matus / Ramírez (2011) 89.

25 En contra Schepeler Raveau (1967) 64. 
ocurre en otras disposiciones en que se requiere una actuación de esas características ${ }^{26}$, entendiendo que el aprovechamiento de una determinada situación -aquí, de los conocimientos y habilidades propios de la profesión-implica una intencionalidad incompatible con el dolo eventual.

Pero además, la remisión que el artículo $345 \mathrm{CP}$ hace a las penas contempladas en el artículo 342 sirve como argumento sistemático para afirmar que también aquí la conducta debe ser realizada con dolo directo e, incluso, con dolo directo de primer grado, es decir, con la intención de matar al feto. Porque la disposición que ahora comentamos se apoya en lo dispuesto en el artículo $342 \mathrm{CP}$ para agravar la responsabilidad por el delito cuando es cometido por determinados profesionales, pudiendo aplicarse sus mismos requisitos típicos. Por eso se entiende que es aplicable la misma graduación de gravedad según si estamos ante un aborto violento, sin consentimiento o con consentimiento de la mujer ${ }^{27}$. Y por eso también resulta lógico incorporar idénticas exigencias subjetivas. Incluir aquí conductas menos graves desde el punto de vista subjetivo significaría una severidad excesiva con los profesionales de la salud, respecto de los cuales la figura ya es doblemente calificada ${ }^{28}$ : en relación con su intervención en el hecho, pues conductas de complicidad son consideradas como formas de autoría, y, sobre todo, en la cuantía de la pena.

\section{3) Código SANitario}

La doctrina penal y la ciencia médica originariamente estimaban que el aborto en Chile estaba permitido cuando obedecía a razones terapéuticas. Esta idea fue confirmada en 1931 con el reconocimiento normativo expreso de esa situación. En efecto, al dictarse el Código Sanitario, el 15 de mayo de 1931, se incorporó al sistema una disposición -primero en el artículo 226 y posteriormente en el artículo 119, a partir del D.F.L. 725 de 1967- que establecía que solo con fines terapéuticos se podrá interrumpir un embarazo. Para proceder a esta intervención se requerirá la opinión documentada de dos médicos-cirujanos.

En cuanto a su naturaleza jurídica, había acuerdo en que se trataba de una causa de justificación. Mayoritariamente era considerada un caso

26 En este sentido, para la expresión abusando de su oficio en el delito de falsificación del art. 193, Politoff / Matus / Ramírez (2011) 566; respecto del art. 231, también, Bullemore / Mackinnon (2007) 195. En el mismo sentido, respecto de los delitos de violación y estupro, Bullemore / Mackinnon (2007) 150 y 156; Garrido Montt (2007) 358 y 378, y Rodríguez Collao, Luis (2001). Delitos sexuales, Santiago: Edit. Jurídica de Chile, pp. 159 y 182.

27 Etcheberry (1997) 105 y Garrido Montt (2007) 117.

28 Politoff / Grisolía / Bustos (2006) 241. 
de estado de necesidad ${ }^{29}$, pero algunos la equiparaban al ejercicio legítimo de una profesión, lo que permitía desligarse de los rigurosos requisitos del primero ${ }^{30}$.

Lo que se entendía por fines terapéuticos fue evolucionando de modo extensivo. En su núcleo, estaba claro que la norma abarcaba los supuestos de aborto terapéutico en sentido estricto, es decir, aquellos casos en que la muerte del feto es provocada como medio necesario para evitar un peligro actual o inminente de muerte para la mujer embarazada. Pero los progresos de la medicina permitieron controlar y reducir esas situaciones extremas, las que se fueron haciendo cada vez más extraordinarias. Aun así, el artículo 119 del Código Sanitario todavía se entendía aplicable en supuestos de peligro futuro para la vida o, incluso, para la salud de la mujer. ${ }^{31}$ Estábamos entonces ante un concepto amplio de aborto terapéutico, referido a supuestos en que la muerte del feto es provocada para evitar la afectación de intereses personalísimos relacionados con la vida, la integridad corporal o la salud de la mujer embarazada.

Posteriormente, la Ley No 18.826, de 1989, modificó ese artículo estableciendo su actual redacción: No podrá ejecutarse ninguna acción cuyo fin sea provocar un aborto.

El principal argumento invocado para proceder a dicha modificación fue el de la obsolescencia de las antiguas indicaciones médicas para la práctica del aborto terapéutico, de tal modo que el caso en que el feto implique un peligro actual o inminente para la vida de la mujer embarazada resultaría absolutamente infrecuente. En consecuencia, se entendió que mantener la autorización genérica para el aborto terapéutico configuraba un resquicio que permitiría realizar abortos fuera de dicha situación excepcional. Para los remotos casos en que el aborto terapéutico -en sentido estricto, se entiende- sí pudiera tener lugar, se estimó que sería suficiente con la aplicación de las disposiciones generales del Código Penal relativas a la exculpación del hecho ${ }^{32}$.

29 Cousiño MacIver (1979). Derecho penal chileno. Parte general, t. II, Santiago: Edit. Jurídica de Chile, pp. 353, 425-430; Labatut (2007) 128 y, particularmente riguroso, EтchebeRRY, Alfredo (1965) Derecho penal. PE, III, 1a ed., Santiago: Carlos E. Gibbs A., editor, pp. 101-102 (referido al art. 226 del DFL 2.226 de 1931) y 2a ed., Editora Nacional Gabriela Mistral, 1976, pp. 73-76 (referido al art. 119 del DFL 725 de 1967).

30 Politoff / Grisolía / Bustos (2006) 249.

31 En este sentido Manríquez Bustos (1963) 43-44; Parada Guzmán (1963) 76; y Politoff / Grisolía / Bustos (2006) 245. Lo restringían solo al peligro para la vida, ЕTcheberry (1965) 101-102 y Fernández Barros, Aurelio (1921). El aborto ante el Derecho penal i la Medicina legal, Santiago: Imprenta i Enc. "La Economía”, p. 28.

32 Informe de la comisión conjunta, oficio No 12, de 16 de agosto de 1989, pp. 370-371. Aunque posteriormente la misma comisión se contradice y arguye que considera "la necesidad de mantener en el Código Sanitario una norma que contemple el aborto terapéutico para casos excepcionalísimos...". 
En todo caso, la disposición solo prohíbe el aborto directamente provocado, es decir, aquel en que la muerte del feto es ocasionada deliberadamente, aunque se realice en una situación de necesidad: la finalidad de la conducta no puede ser la de provocar un aborto. Pero esa referencia a la finalidad de la acción sirve para permitir, indirectamente, conductas realizadas con fines terapéuticos legítimos pese a que exista seguridad de que ellas habrán de tener como efecto, además, la muerte del feto.

\section{4) Código de Ética del Colegio Médico}

En la normativa propia del Colegio Médico se ha producido una evolución similar a la del Código Sanitario.

En efecto, el antiguo Código de Ética de 1983 contemplaba en su artículo 269 la posibilidad de realizar un aborto "solamente cuando se cumplen las condiciones siguientes: a) Se efectúe como medida terapéutica; b) La decisión sea aprobada por escrito al menos por dos médicos escogidos por su competencia; y c) La operación sea efectuada por un médico especialista”.

En su versión de 2004, sin embargo, esa norma desapareció. En su lugar se establecen dos disposiciones que permanecieron vigentes tras la reforma de 2008:

Art. 8. El respeto de la vida humana desde su inicio y hasta su término constituye el fundamento básico del ejercicio profesional médico.

Toda intervención médica realizada durante los nueve meses de gestación, deberá velar siempre por el mejor interés de la madre y del hijo.

Art. 9. El médico no podrá realizar acciones cuyo objetivo directo sea poner fin a la vida de un paciente bajo consideración alguna.

De este modo, puede advertirse que también en su normativa profesional los médicos prohíben tanto el aborto como el homicidio que se realicen con el objetivo directo de poner fin a la vida del feto o del ya nacido, mientras que podrían considerarse permitidas conductas que lleven a ese mismo resultado como consecuencia segura o probable de un tratamiento o intervención que tenga otro objetivo directo, y siempre que se realicen con estricto apego a la lex artis.

\section{5) SOBRE EL REQUISITO DE LA INTENCIÓN ¿DOCTRINA DEL DOBLE EFECTO?}

Las referencias a la finalidad o al objetivo directo de la conducta al prohibir ciertas maniobras que pueden terminar con la vida del nasciturus en el ámbito de la medicina permiten plantear que se estaría aludiendo a la que es conocida como doctrina del doble efecto o voluntario indirecto, 
invocada frecuentemente en el ámbito de la ética médica ${ }^{33}$, pero cuya recepción en nuestro derecho constituiría, por lo menos, una novedad ${ }^{34}$.

Se trata de un principio moral elaborado por los filósofos escolásticos que señala las condiciones que deberían darse para que un acto que tiene dos efectos -uno bueno y uno malo- sea lícito. La formulación clásica, que viene de Jean-Pierre Gury, establece que: "Es lícito poner una causa dirigida a un efecto bueno, aunque de ella se siga un efecto malo, cuando se cumplen las siguientes condiciones, a saber: $1^{\circ}$, que el fin del agente sea honesto; $2^{\circ}$, que la causa sea en sí misma buena o al menos indiferente; $3^{\circ}$, que el efecto bueno se siga de la causa [al menos] con igual inmediatez que el malo; $4^{\circ}$, que el efecto bueno al menos compense al malo" 35 .

Simplificando al máximo la exposición de esta teoría ${ }^{36}$, pueden resumirse dichas condiciones en las siguientes ${ }^{37}$ :

a) que el efecto malo no sea intentado, es decir, que no sea buscado ni como fin ni como medio ${ }^{38}$.

33 Por ejemplo, en una declaración del Departamento de Ética del Consejo General del Colegio Médico de Chile: Aborto: Interrupción del Embarazo como Medida Terapéutica en Casos de Gestantes con Riesgo de Muerte al Continuar la Gravidez, de febrero del año 2003, luego de reconocer que aún persisten algunas indicaciones en que, lamentablemente, no queda otra solución que proceder con la interrupción de la gestación, se entiende que "en estos casos, la intervención -cuya intención es obviamente preservar la vida de la madre- está orientada, al menos, por los principios de beneficencia, de no maleficencia y el respeto a la autonomía de la madre. Si se vulneran los derechos del hijo que está en el seno materno, ello ocurrirá como producto de un acto proporcionado, que lo afecta indirectamente, por cuanto no fue realizado con la intención primaria de dañarlo sino que procurando un mayor bien. Esta acción se denomina de doble efecto y éticamente se valida por el sentido de lo intentado y no de lo que escapa a la intención".

34 La tradición anterior no habría asignado tanta importancia a la intención, a pesar de la referencia subjetiva incluida en el tipo de aborto. En este sentido, BASCUÑán RodríGUeZ (2004) 147.

35 Gury, Jean-Pierre (1850). Compendium theologiae moralis, I, Lugduni-Paisiis, Perisse, p. 5, cit. y traducido por Miranda Montecinos, Alejandro (2008). "El principio del doble efecto y su relevancia en el razonamiento jurídico", en Revista Chilena de Derecho, vol. 35, No 3, p. 489.

36 Una clara exposición sobre su significado e importancia actual se encuentra en Miranda Montecinos (2008) 485-519. Aunque durante mucho tiempo fue un principio reducido al ámbito de la teología moral católica, el autor destaca la importancia que ha adquirido en el ámbito angloamericano y en la jurisprudencia del Common Law (p. 486) y lo presenta como una guía para el razonamiento jurídico (pp. 507 y ss.).

37 Estos requisitos se han enunciado de diversas formas. Por ejemplo, entre nosotros y en relación con la eutanasia, TABoada R., Paulina (2000). "El derecho a morir con dignidad", Acta Bioethica, Universidad de Chile, vol. 6 No 1, p. 99, los presenta en el modo tradicional de cuatro: a) Que la acción sea en sí misma buena o, al menos, indiferente; b) Que el efecto malo previsible no sea directamente querido, sino solo tolerado; c) Que el efecto bueno no sea causado inmediata y necesariamente por el malo; d) Que el bien buscado sea proporcionado al eventual dańo producido.

38 No se trata de realizar una conducta mala como medio para conseguir un fin bueno, porque en ese evento el medio es querido. Para que sea aplicable este principio el efecto malo no es un medio, no es necesario, por sí mismo, para el logro de los propósitos buscados. Más 
b) que exista una razón proporcionalmente grave para realizar el acto y aceptar, permitir o tolerar el efecto malo ${ }^{39}$.

Un caso que ejemplifica bien esta situación es el de la mujer embarazada que padece cáncer y se somete a una histerectomía o a un tratamiento de quimioterapia porque no puede ser tratada de otra manera, aunque prevé con certeza la muerte del feto. En esta situación la mujer no busca esa muerte, su fin no es matar al niño, sino curarse del cáncer. Y no se cura por la muerte del feto, sino por el tratamiento, por lo que la muerte no es un medio, sino un efecto incidental o secundario ${ }^{40}$.

El ánimo con que actúa el agente, por lo tanto, resulta esencial para enjuiciar la licitud de la conducta. Pero esa importancia radical de la intención, propia de una teoría moral, decrece en cierto sentido cuando se trata de un análisis jurídico ${ }^{41}$. Así, para el Derecho basta que concurra una intención principal dirigida a una finalidad permitida, sin perjuicio de que subsistan intenciones secundarias, subordinadas, que puedan ser moralmente reprochables ${ }^{42}$.

En relación con esta doctrina y su compatibilidad con la teoría general del delito y la teoría de las normas, Bascuñán Rodríguez ${ }^{43}$ objeta que resulta poco claro que la presencia de un fin legítimo de la acción restrinja el ámbito de la imputación subjetiva que da lugar al reproche penal, esto es, que por el mero hecho de concurrir un fin legítimo adicional a la acción la responsabilidad se restrinja al dolo directo de primer grado. Más

bien, si ese efecto no se produce, el éxito de su acción aumenta, por lo que deberían ponerse los medios tendientes a evitar que se produzca o a disminuir su daño; así Miranda MonteCINOS (2008) 502.

39 Esa proporcionalidad con la que debe cumplir una acción de doble efecto es de dos clases: (i) una proporción entre la acción y su fin, y (ii) una proporción entre el efecto bueno y el efecto malo. Así se desprende ya de las consideraciones de Santo Tomás sobre la defensa occisiva (Summa thelogica, II-II, q. 64, a. 7, c). Sobre esto Miranda Montecinos (2008) 504.

40 Si el término aborto fuese unívoco en su consideración inmoral, una situación así ni siquiera podría ser llamada aborto, por no ser intencional. "Para los filósofos clásicos las acciones intrínsecamente malas son siempre especies de acciones definidas o descritas en términos intencionales. Aristóteles, por ejemplo, afirma explícitamente estas ideas. Por un lado, sostiene que existen especies de acciones malas en sí mismas (como el adulterio, el robo y el homicidio), cuya realización es, por ello, siempre ilícita. Por otro, afirma que los nombres que designan especies de acciones (v. gr., robo, adulterio, ultraje, homicidio) significan no solo el comportamiento físico que produce determinados efectos exteriores, sino también, y principalmente, la intención con que dichas acciones se realizan”, Miranda Montecinos (2008) 499.

41 Baste recordar la extensa discusión sobre la necesidad o no de un elemento subjetivo -la intención de actuar conforme a derecho- en las causas de justificación.

42 De este modo, "si la mujer grávida se somete a la quimioterapia con la intención de detener el cáncer, pero al mismo tiempo busca la muerte del niño porque su embarazo no fue deseado, entonces el Derecho debe considerar justificada la acción y no debe castigarla como aborto, a pesar de que la moral condene el desorden de la voluntad de la madre", Miranda Montecinos (2008) 504.

43 BAscuñán RodrígueZ (2004) 159-160. 
todavía, lo considera incomprensible, pues la misma teología moral católica estima ilícito el homicidio cometido con dolo eventual, imprudencia e incluso por conexión puramente objetivo-fáctica del resultado con la acción, cuando esta es ilícita in causa (versari in re illicita).

Esta es una objeción que surge desde la visión propia de la dogmática penal, dentro de la cual el análisis de los elementos del delito se hace paso a paso, fraccionando lo objetivo de lo subjetivo. Sin embargo, esa división resulta muchas veces artificiosa y compleja ya en el ámbito penal, como se ha visto reflejado en la evolución de la teoría del delito y, en particular, en la delimitación de lo que se incluye dentro de los criterios de imputación objetiva, según veremos luego.

Por lo demás, esa crítica supone una errónea comprensión de la teoría del doble efecto. En realidad, no es correcto afirmar que permita restringir la responsabilidad por la mera concurrencia de un fin legítimo adicional a la acción. Y esto por dos razones.

En primer lugar, porque desde esta perspectiva no puede reputarse el fin como algo adicional a la acción, sino que es inmanente a la conducta y permite definirla de un modo u otro ${ }^{44}$. La acción moral se inicia con el fin, con la intención, que permite determinar cuál es su especie. No es un mero comportamiento físico que produce un efecto, pues en cuanto se la reputa conducta humana solo se entiende desde el fin que ella persigue. La crítica se sostendría si todo efecto exterior del acto constituyera su objeto o especie; de ser así, todas las "acciones con resultado de muerte" serían homicidio, y toda conducta que pueda vincularse con la muerte del feto, aborto. Pero no se parte de esa base, porque la acción humana no es un simple acaecer físico con consecuencias, sino que procede y se encarna en un propósito interno.

Más todavía, en este ámbito se debe distinguir entre el objeto moral y la intención. Lo primero es el fin o bien a que tiende directamente el acto (fin del acto); es la misma acción que se realiza, que no puede reducirse a un mero acaecer físico, por tratarse de una conducta humana. Cuestión diferente es la intención, que debe entenderse como la finalidad que se persigue al realizar esa conducta (fin del agente) ${ }^{45}$. Ambos pueden coincidir, pero también diferenciarse. Y el hecho de que el agente actúe motivado por un buen fin no significa que pueda realizar cualquier conducta para lograrlo, porque la acción realizada puede ser mala en sí misma, es decir, el fin del acto puede no ser bueno y entonces no está permitido (el fin no justifica los medios).

44 "Los actos morales reciben su especie de lo que está en la intención, y no de lo que es ajeno a ella”, Santo Tomás, Summa Theologica, II-II, q. 64, a. 7.

45 Colom, Enrique / Rodríguez Luño, Ángel (2011). Manual de teología moral. I. Moral fundamental, Roma. Disponible en http://www.eticaepolitica.net/moralfundamental.htm (última visita 10 de agosto de 2011). 
Miranda Montecinos ${ }^{46}$ ofrece dos ejemplos, recogidos de distintos autores, que explican bien el punto. El primero se refiere al ejercicio de la medicina: en un centro hospitalario se presentan seis pacientes agónicos. En un caso, el médico constata que para salvarles la vida necesita administrarles una droga muy escasa. Ahora bien, el primer paciente se salvará con la dosis total con la que cuenta el médico, mientras que los cinco restantes necesitarán un quinto de esa misma dosis. El médico decide repartir la droga entre estos cinco, dejando morir al primero. En un segundo caso, el médico constata que para salvar la vida de los cinco necesita matar al primero y hacer un suero con su cuerpo. Aunque en ambos casos el médico tiene la intención de salvar el mayor número de vidas, solo la primera hipótesis se considera lícita -a pesar de que el médico sabe que su conducta implicará la muerte del primer paciente-; en la segunda, en cambio, la conducta es ilícita en cuanto implica intentar la muerte de un inocente, apuntar hacia ella como parte de un plan, como un medio para alcanzar un fin. El segundo ejemplo está tomado de las prácticas de la guerra: comúnmente se distingue entre el bombardeo estratégico y el bombardeo aterrorizador. En la primera acción, considerada lícita en el moderno Derecho de guerra, un piloto bombardea una fábrica de armamento del enemigo, con el fin de destruir su capacidad productiva, previendo que morirán algunos civiles que viven cerca. En la segunda, considerada ilícita, el piloto bombardea deliberadamente poblaciones civiles con el fin de desmoralizar al enemigo.

En términos penales se ha ido avanzado paulatinamente en esa misma dirección -de interconexión entre lo objetivo y lo subjetivo-, especialmente desde que se adopta una estructura finalista, en cuanto significa considerar que la intención o finalidad es parte integrante de la propia conducta, y por ello debe analizarse a nivel de tipicidad. Pero todavía cuando se analiza la tipicidad objetiva de la conducta, antes de decidir sobre el dolo del agente, es necesario determinar si estamos frente a la creación de un riesgo prohibido por el derecho ${ }^{47}$, y en ese ámbito también tiene sentido incorporar algunos elementos relativos a la intención o conocimiento atribuibles a un determinado rol social ${ }^{48}$.

$46 \quad$ El primero es ofrecido por Foot, Philippa (2001). "The Problem of Abortion and the Doctrine of the ouble Effect”, en Woodward, P. A. (edit.), The Doctrine of Double Effect. Philosophers Debate a Controversial Moral Principle, Notre Dame: University of Notre Dame Press, p. 148; y el segundo corresponde a Quinn, Warren (1989). "Actions, Intentions, and Consequences: The Doctrine of Double Effect", Philosophy and Public Affairs, 18, pp. 336, cit. por Miranda Montecinos (2008) 501.

47 En este sentido Hermosilla, Juan Pablo / Van Weezel, Alex (2009). "Contrapunto: El aborto terapéutico", Revista Chilena de Derecho, vol. 36, No 1, p. 206.

48 De este modo, la distinción actual entre la faz objetiva y subjetiva del tipo se enfrenta con algunas dificultades en el análisis sobre la imputación objetiva del comportamiento, de las que se hace cargo la doctrina, por ejemplo, Cancio Melia, Manuel (2003). "Algunas re- 
La segunda razón para objetar la crítica expuesta es que la doctrina del doble efecto no se limita a considerar únicamente la intención. No puede obviarse el segundo requisito, esto es, el de la gravedad de la razón que impulsa a realizar el acto, pues solo entonces se restringe la imputación subjetiva al dolo directo. Es decir, no cualquier fin legítimo tiene ese efecto, sino solo uno proporcionalmente grave como para aceptar una conducta que, sin ser ilegítima en sí misma, produce o puede producir un efecto malo.

En el fondo, cabe concluir que a través de este principio lo que se establece es una excepción respecto de la responsabilidad por la propia conducta. La regla general es la ilicitud de cualquier conducta de la que se derive la muerte de otra persona, nacida o no nacida, responsabilidad que no desaparece por el hecho de que la conducta se cometa con dolo eventual o imprudencia. Pero la presencia de varios requisitos copulativos -fin legítimo del acto, recta intención y proporcionalidad- hacen variar la valoración de la conducta, considerándola permitida.

En atención a esto último podemos advertir, eso sí, que la referencia a esta teoría del doble efecto en nuestro ordenamiento jurídico solo resulta parcial, pues las disposiciones del Código Sanitario y del Código de Ética del Colegio Médico nada dicen sobre la razón que motiva a realizar el acto. Se entiende, dado el contexto en que se insertan las normas, que serán razones terapéuticas, pero carecen de toda exigencia sobre su gravedad. Según la doctrina moral, en cambio, esas razones deben superar un juicio de proporcionalidad para poder aceptar, permitir o tolerar el efecto malo $^{49}$.

Aunque puede parecer sorprendente, dada la tan asentada idea de la separación entre derecho y moral, nuestro sistema no sería el único que ha asignado relevancia jurídica a esta teoría moral, sino que ella ha sido invocada en la solución de controversias similares en diversos países en los últimos tiempos ${ }^{50}$.

flexiones sobre lo objetivo y lo subjetivo en la teoría de la imputación objetiva”, en Montealegre Lynett (coordinador): Libro homenaje al profesor Günther Jakobs. El funcionalismo en el Derecho penal, Bogotá: Universidad Externado de Colombia, pp. 211 a 228, y KindHauser, Urs (2004). "Imputación objetiva y subjetiva en el delito doloso" (trad. Pastor Muńoz), Cuestiones actuales de Derecho penal general y patrimonial, I Jornada de Derecho penal, Piura: Facultad de Derecho de la Universidad de Piura, pp. 55-71.

49 Requisito que parece olvidado en algunas de las objeciones que se formulan a esta doctrina.

50 La aplicación jurídica de este principio se ha producido tanto en el Derecho internacional de la guerra como, fundamentalmente, en relación con la eutanasia. En el caso Vacco vs. Quill (1997), la Corte Suprema de los Estados Unidos alude a él por primera vez en el fundamento de un fallo. En Rodríguez vs. British Columbia (1993) la Suprema Corte de Canadá hace lo propio. Ambas apelan a la distinción entre intención y efecto colateral para justificar el distinto tratamiento que se le da a la eutanasia o al suicidio asistido por una parte, y a los tratamientos paliativos que aceleran o pueden acelerar la muerte, por la otra. En el Derecho inglés, las principales conclusiones que resultan de la aplicación del principio al problema 
Por otra parte, tampoco resulta una solución discordante con la regulación contemplada en el Código Penal sobre el aborto. En realidad existe coincidencia entre lo que dispone la legislación sanitaria, el Código de Ética del Colegio Médico y el propio Código Penal. Las dos primeras proscriben todo aborto directamente procurado, lo que implica que la prohibición queda restringida a aquel ocasionado con la intención específica de matar al feto, intención que coincide con el dolo directo de primer grado. Por su parte, las expresiones maliciosamente y abusando de su oficio que contemplan los artículos 342 y 345, respectivamente, implican la misma exigencia, sancionando únicamente las conductas realizadas con dolo directo, el que bien puede limitarse, incluso, solo al de primer grado, de conformidad con lo expresado al analizar ese tipo. Aunque nuestra legislación penal contemple otras formas de dolo en la disposición del artículo 343, ello solo dice relación con el aborto violento. Los supuestos de aborto sin empleo de violencia (art. 342 No 2 y 3), entre los que se ubican las intervenciones realizadas con fines terapéuticos, únicamente son punibles cuando se cometen con la precisa intención de dar muerte al feto. Si la conducta es realizada con una intención diversa, aunque con la seguridad de que el feto morirá o aceptando que ello ocurra, resulta impune por atipicidad subjetiva.

Al igual que en la legislación sanitaria, puede afirmarse que el Código Penal solo recoge el primer requisito de la doctrina del doble efecto -que el efecto malo no sea buscado ni como fin ni como medio-, pero omite el segundo relativo a la proporcionalidad entre la razón que lleve a realizar el acto y los efectos que origina. En relación con el artículo 119 del Código Sanitario esta cuestión resulta mitigada por el contexto terapéutico en que se inserta la norma. En la disposición penal, en cambio, esa intención principal que excluye el dolo directo y hace impune la conducta puede ser cualquiera -un tratamiento de belleza, un entrenamiento deportivo, etc.-, aunque no tenga la gravedad necesaria como para aceptar el efecto secundario que ocasiona.

Para comprender bien las consecuencias penales de lo hasta aquí explicado, es fundamental determinar cuál es el rol dogmático que se puede atribuir a la conducta que provoca un aborto cuando es realizada bajo las condiciones requeridas por la doctrina del doble efecto. De este modo precisaremos mejor los requisitos relativos a la intención en el delito de aborto.

de la eutanasia han sido recogidas en el Informe del Comité Selecto sobre Ética Médica de la Cámara de los Lores (1994). Algo similar ocurre en el Derecho australiano, en que una enmienda del año 2003 al Código Penal de Queensland (1899) describe expresamente la modificación formulada como una "promulgación legal del principio del doble efecto para los cuidados paliativos". Referencias en Miranda Montecinos (2008) 509-510. 


\section{6) UN PROBLEMA DE IMPUTACIÓN OBJETIVA}

Pese a la coincidencia que existe en torno a la intención, es evidente que el contenido normativo de las disposiciones del Código Penal es muy diverso del que corresponde al artículo 119 del Código Sanitario. Las primeras delimitan la conducta penalmente prohibida, mientras que esta última fija los márgenes del ejercicio de la medicina, con lo que faculta para decidir si una conducta puede considerarse permitida en el contexto de dicho ejercicio.

Ya hemos visto que según los artículos 342 y 345 CP la falta de intención significaría la atipicidad subjetiva de la conducta, por lo que no es necesario invocar una causa de justificación para amparar una conducta que no ha estado dirigida a provocar la muerte del feto ${ }^{51}$.

Pero en el marco de una intervención terapéutica esa atipicidad no se explica únicamente desde un punto de vista subjetivo. Cuando se trata de una actividad médica realizada con fines terapéuticos, en que la muerte del feto sobreviene de modo indirecto, más que atipicidad subjetiva lo que se excluye es la imputación objetiva del comportamiento. En efecto, aunque no es un tema totalmente pacífico, gran parte de la doctrina entiende que las intervenciones curativas practicadas con arreglo a la lex artis y con resultado positivo no configuran los tipos de lesiones, a lo que otros ańaden que la atipicidad no depende del éxito o no de la intervención, pues es un asunto que se juzga ex ante, y desde esta perspectiva "la atipicidad de la conducta del médico importa el reconocimiento de la especial valoración social de su función, que no es inhibida o tolerada, sino estimulada por la ley" 52 . Desde esta perspectiva, entonces, son conductas que no requieren apoyarse en una causa de justificación, pues son socialmente adecuadas o, mejor, parte del riesgo permitido ${ }^{53}$. Esta valoración no

51 En esto se equivoca Garrido Montt (2007) 118, n. 225. Parte considerando que la conducta del médico en estas circunstancias sería atípica desde una perspectiva objetiva, por limitarse a cumplir con su función. Pero ańade que si no se comparte esa opinión, "esa actividad profesional se debe encuadrar en la justificante del art. 10 No 10 (ejercicio legítimo de un oficio) porque su finalidad no es causar un aborto, sino salvar una vida". Lo cierto es que, en la hipótesis que él describe, si se afirma que existe tipicidad objetiva, de todos modos la conducta sería subjetivamente atípica.

52 Politoff / Grisolía / Bustos (2006) 270.

53 Entre nosotros parece ser opinión unánime, en ese sentido, además de los recién citados, Cury Urzúa, Enrique (2005). Derecho penal. Parte general, 8a ed., Santiago: Universidad Católica de Chile, pp. 371-372; Künsemüller Loebenfelder, Carlos (1986). "Responsabilidad penal del acto médico", Revista Chilena de Derecho, vol. 13, p. 263 (aunque lo fundamenta desde una perspectiva más bien subjetiva); Politoff / Matus / Ramírez (2011) 238. En el extranjero, por la opinión dominante, Mir Puig, Santiago (2004). Derecho penal. Parte general, 7a ed., Montevideo-Buenos Aires: Bdef, L 18/49, p. 488; Jаковs, Günther (1998). La imputación objetiva en Derecho penal, Lima: Grijley, p. 27, y Roxin, Claus (1997). Derecho penal. Parte general, I (trad. de la 2a ed. alemana por Luzón Peña, Díaz y García Conlledo, Vicente Remesal), Madrid: Civitas, $\$ 11 / 57$, p. 372. 
cambia ni siquiera cuando es previsible la producción de un resultado lesivo $^{54}$. En particular entonces, puede afirmarse que "el médico que cumple su deber profesional haciendo lo que el estado de la ciencia médica le indica hacer para intentar salvar ambas vidas, crea para la criatura (y para su madre) un riesgo que está permitido por el ordenamiento jurídico. Se trata de una conducta socialmente adecuada, y por lo tanto ya desde un comienzo no comprendida en el tipo penal" 55 . Entendemos que este es el nivel en el que se mueve lo estipulado en el artículo 119 del Código Sanitario: el de la imputación objetiva de la conducta. Como las intervenciones terapéuticas realizadas con el cuidado debido y de conformidad con la lex artis están amparadas en el riesgo permitido, lo que esa norma dispone es que solo queda fuera de ese ámbito, es decir, que no puede ampararse en el riesgo permitido, la conducta cuyo fin sea provocar un aborto. En otras palabras, esto significa que se admite como actividad terapéutica permitida toda aquella que se realiza con una finalidad curativa, aunque la muerte del feto sea previsible o incluso segura, excluyendo únicamente la conducta encaminada directamente a ese objetivo.

Que un elemento "subjetivo" como la intención o finalidad directa con que se desarrolla la conducta pueda afectar el juicio de imputación objetiva no debe sorprender, pues este no resulta un elemento ajeno a este nivel de la teoría del delito. Tanto así, que una de las críticas que se formulan contra la teoría de la imputación objetiva se refiere precisamente a si tiene en realidad un carácter "objetivo", en la medida en que, por ejemplo, se tienen en cuenta los conocimientos y facultades superiores a los de un sujeto ideal perteneciente al contexto social en el que actúa el sujeto ${ }^{56}$. En relación con esa crítica, y aunque es un problema cuya complejidad excede el cometido de estas páginas, baste con advertir que en el ámbito de la imputación objetiva lo que se cuestiona es si existe una perturbación general-objetiva, es decir, si se produce una perturbación social penalmente relevante; y en ese nivel de análisis puede tener relevancia algún elemento que esté "dentro de la cabeza" del agente. "En este sentido, 'objetivo' significa concreción de la norma conforme a los patrones generales de un sujeto en un determinado papel social" 57 . En definitiva, la diferencia entre las esferas objetiva y subjetiva no depende de que los elementos se hallen dentro o fuera de la mente del ser humano, "por el contrario, mientras lo objetivo será el estudio de la conducta del hombre en cuanto

\footnotetext{
54 En este sentido Silva SÁnchez, Jesús María (1999). Medicinas alternativas e imprudencia médica, Barcelona: J. M. Bosch Editor, pp. 11-12.

55 Hermosilla / Van Weezel (2009) 206. También se inclinan por la atipicidad de la conducta Garrido Montt (2007) 118, n. 225 y Bullemore / Mackinnon (2007) 52, aunque asignando un contenido mucho más amplio a la conducta amparable en la lex artis, cuestión a la que nos referiremos luego.

56 Sobre esta cuestión, Cancio Melia (2003) 221 ss.

$57 \quad$ Cancio Melia (2003) 226.
} 
ser social, lo subjetivo hará referencia al análisis del comportamiento del hombre en cuanto individuo" 58 .

En este sentido, lo "propiamente" subjetivo no tiene relevancia. Así, por ejemplo, si un médico realiza un tratamiento curativo directamente encaminado a curar a la mujer embarazada (una quimioterapia, por ejemplo), no está creando un riesgo penalmente relevante. Su conducta está permitida con total independencia de que ese médico, además, desee o se complazca con la muerte del nasciturus, pues el fin de la acción no era el de procurar esa muerte.

De nuevo aquí advertimos, entonces, que la doctrina del doble efecto no resulta discordante con las consideraciones sistemáticas de la teoría del delito. Según esta teoría, y en virtud de una serie de requisitos copulativos, una conducta no puede considerarse prohibida. Desde el punto de vista de la terminología, en el caso que ahora nos interesa, ni siquiera debería seguir llamándose aborto. En otras palabras, se plantea como un asunto de imputación previo a la justificación.

A veces la terminología empleada para referirse a las situaciones que resultan permitidas en virtud de la doctrina del doble efecto conduce a la idea de que se estaría ante supuestos de justificación, porque se habla de que entonces la conducta es lícita. Sin embargo, eso no debe interpretarse como si se tratase de conductas en principio prohibidas pero excepcionalmente justificadas, sino que la expresión también comprende los comportamientos que ni siquiera resultan penalmente prohibidos en un primer juicio valorativo, pues no suponen la creación de un riesgo prohibido por el derecho ${ }^{59}$.

58 Reyes Alvarado, Yesid (2002). "El concepto de imputación objetiva”, Derecho penal contemporáneo, No 1, octubre-diciembre, p. 31.

59 En consecuencia, pierde sentido otra de las críticas formuladas a la doctrina del doble efecto por BASCuñán Rodríguez (2004) 159-160. Advierte este autor que en el ámbito penal, lo central para excluir la ilicitud de la acción es la concurrencia de una situación justificante (objetiva), mientras que las exigencias cognitivas y volitivas se relacionan solo con la concurrencia de esa situación, no con la realización del supuesto de hecho de la norma punitiva. Por eso, un homicidio en legítima defensa no deja de estar justificado porque haya sido cometido con dolo directo; es lícito matar para defenderse. Además de la improcedencia de la crítica cuando estamos refiriéndonos al riesgo permitido en el contexto de la actividad terapéutica, podemos afirmar que ella no se corresponde con lo que la teoría del doble efecto establece. En efecto, BASCuŃán Rodríguez entiende que conforme a esta doctrina "no es lícito matar a otro con motivo de la defensa -para defenderse-, pero sí con ocasión de ella -al defenderse-" (p. 159), de tal modo que la defensa legítima supondría una ausencia de intencionalidad en la acción homicida. Pero eso es una errónea interpretación que algunos proponen del mismo texto de Santo Tomás sobre la legítima defensa. En la Summa Theologica, II-II, q. 64, a. 7, quien afirma que es lícito matar a otro defendiéndose ("utrum liceat alicui occidere hominem seipsum defendendo") y no lo sería para defenderse ("ut seipsum defendat"). El asunto es que esta última afirmación la hace en directa alusión al a. 2 donde establece que la autoridad puede condenar a muerte al malhechor, pero es la autoridad la única que puede hacerlo. Esta facultad de la autoridad es la que justifica que el soldado, habiendo recibido la orden de combatir al enemigo, mate a uno que no le está atacando en ese 
Cuando el Código Sanitario y el Código de Ética del Colegio Médico prohíben las conductas directamente encaminadas a producir la muerte del nińo no nacido, están excluyendo esos comportamientos de lo que puede considerarse permitido dentro de la actividad médica. Están, en consecuencia, delimitando el espacio de riesgo permitido en el que una conducta no se considera, siquiera, perturbadora socialmente. Ni aun cuando el resultado lesivo aparezca como consecuencia segura del actuar. En este sentido puede afirmarse, incluso, que esta regulación es más laxa que otras al delimitar el ámbito de aplicación del riesgo permitido, toda vez que este normalmente resulta excluido cuando concurre el conocimiento cierto sobre la producción del resultado lesivo. Aquí, en cambio, esa opción sigue quedando amparada en el ejercicio de la medicina como un riesgo socialmente aceptado.

Interesa destacar, en este sentido, que la normativa que ahora analizamos alude más a las características de la conducta que a las particularidades de su autor. Lo que se prohíbe es una acción cuyo fin -de la conducta considerada en sí misma- sea provocar un aborto, por lo que estaría aludiendo al objeto o fin del acto, distinguible de la finalidad del autor, tal como hemos explicado antes.

Lo que queda prohibido, como contrario a la práctica médica aceptable, es la conducta que está directamente encaminada a provocar la muerte del no nacido, aunque se realice con una finalidad terapéutica respecto de la vida de la madre ${ }^{60}$.

Como se desprende de lo dispuesto en el Código de Ética, para el médico tanto el nińo como la madre son sus pacientes, y los esfuerzos

momento, tal como lo hace el verdugo con el condenado. Es en ese contexto en que se afirma la ilicitud de matar a otro "para defenderse", entendiendo que a diferencia de lo que ocurre con el verdugo y el soldado, en general no se puede matar para defenderse de alguien que en ese momento no está atacándole. Pero para la doctrina moral, al igual que para la penal, un homicidio en legítima defensa está justificado aunque se actúe con dolo directo. De hecho, Santo Tomás comienza su explicación sobre la justificación de la legítima defensa afirmando que "del acto de alguien que se está defendiendo pueden darse dos intenciones: la primera, la conservación de la propia vida; la segunda, la muerte del atacante", es decir, no excluye esa intención de dar muerte, sino que solo la subordina a la primera.

60 En contra, Bullemore / Mackinnon (2006) 50-52, estiman que se puede preferir la vida de la madre por sobre la del feto en todo caso, y que la conducta del médico será atípica en la medida en que cuente con el consentimiento de la madre o del padre. Para justificar esta conclusión aluden a un concepto amplio de lex artis referido no solo a reglas y procedimientos médicos, sino también a principios. Especialmente, el de la relación médico-paciente como principio rector, que permitiría prescindir del contenido del art. 119 CS. Pero no es aceptable esta conclusión puesto que no solo pasa por alto lo que dispone ese artículo, sino que supone invocar ese principio -en contra de otras disposiciones de la propia lex artis-, como si el único paciente fuese la madre. Por el contrario, como tanto la madre como el hijo son pacientes (el art. 8 inciso $2^{\circ}$ establece que toda intervención médica realizada durante los nueve meses de gestación, deberá velar siempre por el mejor interés de la madre y del hijo) ese mismo principio rector de la medicina es el que prohíbe reputar atípica la conducta del médico que pretende la muerte del feto. 
por salvarlos no pueden llegar al extremo de matar a uno para preservar la vida del otro. Por eso dicho Código afirma que "el médico no podrá realizar acciones cuyo objetivo directo sea poner fin a la vida de un paciente bajo consideración alguna". Lo mismo ocurre en relación con la actividad terapéutica y los riesgos que implica para la vida de un paciente adulto. No configuran un riesgo relevante las intervenciones de carácter terapéutico, aun cuando se prevea la posibilidad o incluso se tenga la certeza de que se producirá la muerte. Quedan prohibidas, en cambio, las conductas que tengan como objetivo directo la muerte del paciente, aunque se invoque una finalidad terapéutica respecto del mismo (por ejemplo, para evitarle mayores sufrimientos) o de otros pacientes.

Volviendo a los ejemplos ya citados, en el caso de los seis pacientes agónicos no resulta un riesgo prohibido que el médico reparta la droga necesaria entre los cinco que requieren un quinto de la dosis, dejando morir al que requeriría la dosis total disponible. Pero sería imputable objetivamente -riesgo no permitido- si matase a uno para fabricar con su cuerpo un suero que permitiría salvar a los demás.

\section{7) POSIBILIDADES DE JUSTIFICACIÓN O EXCULPACIÓN}

Considerando la prohibición impuesta por el artículo 119 del Código Sanitario, cabe preguntarse si ella significa también que resulte excluida cualquier posibilidad de justificación respecto de una conducta directamente encaminada a producir un aborto. Mayoritariamente se ha entendido de este modo ${ }^{61}$, confundiendo diversos niveles de valoración. Porque debemos insistir en que la normativa analizada no se refiere a las posibilidades de justificación, sino a la configuración de lo prohibido y permitido dentro del ejercicio de la actividad médica como comportamiento socialmente adecuado.

Para entenderlo mejor, consideremos lo que sucede en relación con los pacientes adultos, pues también está prohibida cualquier conducta del médico cuyo objetivo directo sea poner fin a la vida de uno de ellos. ¿Significa esto que se excluyen para los médicos las posibilidades de justificación respecto del eventual homicidio de un paciente? Evidentemente que no. La afirmación contenida en la normativa médica solo tiene por objeto regular

61 Así lo conciben, por ejemplo, Cea Egaña, José Luis (2004). Derecho constitucional chileno, II, Santiago: Ediciones Universidad Católica de Chile, p. 95.; Moнor Abuauad, Salvador (1990). "Reflexiones en torno a la prohibición del aborto en Chile", en VV.AA: XX Jornadas. Chilenas de Derecho Público, t. II, Valparaíso: Edeval; Precht Pizarro, Jorge (1992). "Consideraciones ético-jurídicas sobre el aborto terapéutico", Revista Chilena de Derecho, 1992, No 19, p. 516; Romo Pizarro, Osvaldo (1992). Medicina legal. Elementos de Ciencias forenses, Santiago: Edit. Jurídica de Chile. También Bascuñán Rodríguez (2004) 164. 
la actividad médica en cuanto tal, y en ese contexto es que se afirma que no puede realizarse ninguna acción cuyo objetivo directo sea poner fin a la vida de un paciente. Pero si en alguna ocasión un paciente ataca a su médico, es obvio que este puede defenderse legítimamente y, si es necesario, matar a su atacante. Nadie diría que infringe lo dispuesto en el Código de Ética.

Lo propio sucede en relación con la muerte del niño no nacido. La normativa sanitaria y médica no excluye a priori la concurrencia de cualquier causa de justificación ${ }^{62}$, sino que su cometido es precisar el límite del riesgo permitido como ejercicio de la actividad terapéutica de la medicina. En esa medida, solo impide invocar como justificante la del artículo 10 No 10 CP más allá de lo dispuesto en la normativa analizada, en cuanto la propia regulación del ejercicio de la profesión de médico está prohibiendo la realización de conductas directamente encaminadas a provocar la muerte del feto, aun cuando tengan una finalidad terapéutica respecto de la vida de la mujer ${ }^{63}$.

La concurrencia de otras causas de justificación -como la legítima defensa o el estado de necesidad- habrá de decidirse de conformidad con los requisitos que les son propios, sin pretender ampararse en la finalidad terapéutica y la lex artis de los médicos. Que esas causales no sean aplicables en relación con el delito de aborto, por tanto, no se deberá a lo dispuesto en el artículo 119 CS ni en el nuevo Código de Ética Médica ${ }^{64}$. Si no procede legítima defensa es porque no puede afirmarse una agresión ilegítima de parte del feto; en realidad, no existe siquiera agresión dado que el feto no es capaz de acción. También se excluye el estado de necesidad justificante, incluso el defensivo, en la medida en que no se puede atribuir al feto una organización normativamente deficiente como para

62 No debe verse una coincidencia entre lo propuesto y la tesis planteada en su momento por Sanhueza Romero, Juana (1990). "Tratamiento jurídico del aborto terapéutico", Revista de Derecho, U. de Concepción, $N^{\circ} 187$, pp. 32-33, quien atribuía al art. 119 CS la función de derogar la presunción de legitimidad de la conducta abortiva terapéutica (antes permitida expresamente) y reafirmar el indicio de antijuridicidad del tipo de aborto, dejando al aborto terapéutico en la misma situación que existía a la época de dictación del Código Penal. De este modo, el art. 119 CS no sería más que una reiteración de la norma que prohíbe el aborto en el Código Penal, redundante e inútil, mientras que aquí se le reconoce un efecto normativo relevante en el contexto de la lex artis que modifica parcialmente la situación del aborto terapéutico, que ya no puede entenderse justificado dentro del art. 10 No 10 CP.

63 El art. 119 del Código Sanitario constituye un antecedente insoslayable al precisar el contenido de la lex artis, que prima por jerarquía y por especialidad sobre las normas reglamentarias o puramente éticas de signo contrario según Horvitz Lennon / Soto Piñeiro (2007) 88 n. 28. En igual sentido, destaca que se trata de lex artis de rango legal Bascuñán Rodríguez (2004) 164 y Urria Hering, Pablo (1993). Fundamentación médico legal del aborto terapéutico, Memoria, Universidad Católica de Valparaíso (inédita), pp. 66, 71 y 78.

64 No puede afirmarse, en consecuencia, que el art. 119 CS restrinja la posibilidad de aplicación del estado de necesidad defensivo justificante respecto del feto. Idea a partir de la cual BASCUŃÁn Rodríguez (2004) 173, sostiene la "manifiesta inconstitucionalidad" de dicha disposición, por contradecir el principio de igualdad ante la ley, en la medida en que esa justificación sí sería procedente respecto de cualquier persona. 
atribuirle la creación del peligro que amenaza a la madre ${ }^{65}$. Pero estas cuestiones merecen un tratamiento particular del que nos hemos hecho cargo en otro trabajo ${ }^{66}$.

Por último, cabe advertir que si la muerte del feto se produce por razones terapéuticas, pero no queda comprendida dentro del riesgo permitido propio de la actividad médica ni procede una causa de justificación, habrá de evaluarse la eventual concurrencia de una causa de exculpación. Algunos niegan la posibilidad de exculpar a terceros y, en particular, al médico que realiza el aborto, con el argumento de que la exculpación es personalísima, que no se comunica, y que no sería el médico quien se encuentra en peligro por la presencia del feto ${ }^{67}$. Sin embargo, esa construcción supone reducir la inexigibilidad a situaciones de coacción psíquica como fenómeno ontológico. Entendemos, en cambio, que lo decisivo para enjuiciar la exigibilidad o inexigibilidad de una conducta es el conflicto de motivos inherente a la situación de necesidad, el que debe valorarse objetivamente ${ }^{68}$. Lo que hay que determinar es si el médico, enfrentado a una situación extrema de necesidad, es o no es motivable por las normas penales y, por ende, si es o no es culpable. En este sentido no estamos "comunicando" la situación de inexigibilidad de la madre al médico, sino que este último se ve también enfrentado a un conflicto de motivos, y aunque él no sufre ninguna forma de miedo (que puede ser insuperable para la mujer embarazada según la gravedad de la situación), le es plenamente aplicable la situación de fuerza moral ${ }^{69}$.

65 El estado de necesidad justificante defensivo supone que la salvaguarda del interés amenazado se logra a través de una intervención que afecte los intereses de un tercero de quien emana el peligro que amenaza. Aunque se trata de un tema poco desarrollado y muchos se conforman con que exista una vinculación fáctica entre el tercero y el peligro, al atender al fundamento último de esta situación justificante, resulta que este debería radicar en el principio de responsabilidad. En consecuencia, solo puede hablarse de estado de necesidad defensivo cuando el peligro puede reconducirse en términos de imputación objetiva a actos previos de gestión organizativa. Lo contrario -conformarse con un vínculo fáctico- convertiría al subsistema de atribución de responsabilidad en que consiste el estado de necesidad defensivo, en un sistema irracional, condicionado por meras relaciones de causalidad. En este sentido, Coca Vila, Ivó (2011). "Entre la responsabilidad y la solidaridad. El estado de necesidad defensivo", InDret, Revista para el análisis del Derecho, 1.11, Barcelona, pp. 1-41. En consecuencia, no puede invocarse el estado de necesidad defensivo en contra del feto.

66 Ossandón, Magdalena (2011) "Aborto y justificación". Revista Chilena de Derecho, vol. 39, No 3 (en prensa).

67 Así Bascuñán Rodríguez (2004) 152 y 156, y Urria Hering (1993) 73-74. Debido a esto es que en la jurisprudencia alemana se invocaba el estado de necesidad justificante supralegal para cubrir la situación del médico.

68 En este sentido Silva Sánchez, Jesús María (1999). "Sobre las actuaciones en una 'situación de necesidad' que no implican deberes de tolerancia”, en Luzón Peña et al. (directores): Cuestiones actuales de la teoría del delito, Madrid: McGraw-Hill, p. 175.

69 Admiten la posibilidad de exculpación respecto de la conducta del médico Politoff / Grisolía / Bustos (2006) 260; Politoff / Matus / Ramírez (2011) 98, y Sanhueza Romero (1990) 32. Lo considera difícil por tratarse de un tercero, Etcheberry (1997) 109. 
Pero si quedase todavía alguna duda a este respecto, la incorporación de una eximente amplia de estado de necesidad en el artículo 10 No $11 \mathrm{CP}$ hace innecesaria mayor discusión sobre el punto, en cuanto es evidentemente aplicable esa eximente y con carácter exculpatorio, al médico que practica el aborto por graves razones terapéuticas ${ }^{70}$.

\section{CONCLUSIONES}

Los tipos penales de aborto contemplados en los artículos 342 y 345 $\mathrm{CP}$ requieren como elemento subjetivo que el autor realice la conducta con la intención precisa de que se produzca la muerte del nasciturus. Las exigencias de un actuar malicioso y con abuso del oficio, respectivamente, deben ser interpretadas en este sentido. Aplicando la distinción tradicional de dolo, esto supone que se debe realizar la conducta con dolo directo de primer grado, pues de lo contrario la conducta será subjetivamente atípica.

Cuando estamos en un contexto terapéutico, la conducta del profesional de la salud que no persigue como objetivo directo la muerte del niño no nacido, es objetivamente atípica como parte del riesgo permitido inherente a la actividad médica, siempre que la intervención se realice de conformidad con la lex artis, y aun cuando esa muerte aparezca como consecuencia segura de su actuar.

Si la muerte del feto ha sido intencional pero para salvar la vida de la madre, la eventual concurrencia de una causa de justificación habrá de decidirse según sus propios requisitos. El artículo 119 del Código Sanitario solo excluye la posibilidad de invocar el ejercicio legítimo de la medicina, en cuanto dicha disposición constituye parte de la regulación de la profesión médica de rango legal. Si no resulta aplicable ninguna causa de justificación, generalmente procederá la exculpación.

\section{BibLiOgRAFÍA}

Aldunate Lizana, Eduardo (2008). Derechos fundamentales, Santiago: LegalPublishing.

Araya Rivera, Carmen (1963). El aborto, Santiago: Edit. Universitaria. Amunátegui Stewart, Felipe (1961). "Maliciosamente" y "A sabiendas" en el Código Penal Chileno, Santiago: Edit. Jurídica de Chile.

70 Del análisis sobre la naturaleza justificante o exculpatoria de esa eximente y su aplicabilidad al aborto. Véase Ossandón (2011). 
BAscuñán Rodríguez, Antonio (2004). "La licitud del aborto consentido en el Derecho chileno", Derecho y Humanidades, U. Chile, No 10, pp. 143-181.

(2004 a) "La píldora del día después ante la Jurisprudencia", Estudios Públicos $\mathrm{N}^{\circ}$ 95, pp. 43-89.

Bordalí, Andrés / ZúñIga, Yanira (2009). "Análisis del fallo del Tribunal Constitucional sobre la píldora del día después", Anuario de Derechos Humanos, No 5, pp. 173-182.

Bullemore, Vivian / Mackinnon, John (2007). Curso de Derecho penal. Parte especial, Tomo III, 2a ed., Santiago: LexisNexis.

Cancio Melia, Manuel (2003). "Algunas reflexiones sobre lo objetivo y lo subjetivo en la teoría de la imputación objetiva", en Montealegre, Lynett (coord.): Libro homenaje al profesor Günther Jakobs. El funcionalismo en el Derecho penal, I, Bogotá: Universidad Externado de Colombia, pp. 211-228.

Carrasco Delgado, Sergio (1988). "La garantía constitucional del derecho a la vida del que está por nacer", en VV.AA: XVIII Jornadas de Derecho Público, Universidad de Concepción, pp. 39-54.

Cea Egaña, José Luis (2004). Derecho constitucional chileno, II, Santiago, Ediciones Universidad Católica de Chile.

Coca Vila, Ivó (2011). "Entre la responsabilidad y la solidaridad. El estado de necesidad defensivo", InDret, Revista para el análisis del Derecho, 1.11, Barcelona, pp. 1-41.

Colom, Enrique / Rodríguez Luño, Ángel (2011). Manual de teología moral. I. Moral fundamental, Roma. Disponible en http://www. eticaepolitica.net/moralfundamental.htm

Corral Talciani, Hernán (2005). "El concepto jurídico de persona y su relevancia para la protección del derecho a la vida", Ius et Praxis, U. de Talca, Año 11, No 1, pp. 37-53.

Cousiño MacIver, Luis (1975-1979). Derecho Penal chileno, I y II, Santiago: Edit. Jurídica de Chile. de Chile.

(1949). Manual de medicina legal, I, Santiago: Edit. Jurídica

Cury Urzúa, Enrique (2008). "El estado actual de la doctrina y jurisprudencia nacionales en torno a los problemas del error de prohibición”, en VV.AA: Delito, pena y proceso. Libro homenaje a la memoria del profesor Tito Solari Peralta, Santiago: Edit. Jurídica de Chile, pp. 237-248.

(2005). Derecho penal. Parte general, $8^{a}$ ed., Santiago: Universidad Católica de Chile.

Diez Urzúa, Sergio (1999). Personas y valores. Su protección constitucional, Santiago: Edit. Jurídica de Chile. 
Dworkin, Ronald (1994). El dominio de la vida: una discusión acerca del aborto, la eutanasia y la libertad individual (trad. Caracciolo/ Ferreres), Barcelona: Ariel.

Etcheberry, Alfredo (1997). Derecho Penal. Parte Especial, Tomo III, $3^{a}$ ed., Santiago: Edit. Jurídica de Chile.

Evans de la Cuadra, Enrique (2004). Los Derechos Constitucionales, t. I, $3^{a}$ ed., Santiago, Edit. Jurídica de Chile.

Evans Espiñeira, Eugenio (2000). Relación de la Constitución Politica de 1980, Santiago: ConoSur.

Fermandois Vöhringer, Arturo (2004). "La píldora del día después: aspectos normativos", en Estudios Públicos N 95, pp. 91-118.

Figueroa García-Huidobro, Rodolfo (2007). "Concepto de persona, titularidad del derecho a la vida y aborto", Revista de Derecho, Universidad Austral de Chile, vol. XX, No 2, pp. 95-130.

Figueroa Yáñez, Gonzalo (2001). Derecho civil de la persona: del genoma al nacimiento, Santiago, Edit. Jurídica de Chile.

Fuenzalida Zúñiga, Carmen Gloria (1998). "Protección jurídica del embrión en la legislación chilena", Revista Chilena de Derecho, PUC, vol. 25, No 4, pp. 827-850.

García Cavero, Percy (2008). Lecciones de Derecho penal, Parte General, Lima: Grijley.

Garrido Montt, Mario (2007). Derecho penal. Parte Especial, Tomo III, $3^{a}$ ed., Santiago: Edit. Jurídica de Chile.

Gómez Bernales, Gastón (2005). Derechos fundamentales y recurso de protección, Santiago, Ediciones Universidad Diego Portales.

Guzmán Brito, Alejandro (2001). El Derecho privado constitucional de Chile, Valparaíso, Ediciones Universitarias de Valparaíso.

Hernández Basualto, Héctor (2004). "El delito de lavado de dinero", Informe en Derecho para la Unidad Especializada de Lavado de Dinero y Delitos Económicos de la Fiscalía Nacional del Ministerio Público. Disponible en http://www.ministeriopublico.cl/ RepositorioMinpu/Archivos/minpu/Informes\%20en\%20derecho/ HECTOR\%20HERNÁNDEZ\%20lavado.doc

Horvitz Lennon, María Inés / Soto Piñeiro, Miguel (2007). "Consideraciones críticas sobre la regulación del delito de aborto en el anteproyecto de nuevo Código penal elaborado por el foro del Ministerio de Justicia”, Revista de Estudios de la Justicia, U. Chile, No 9, pp. 75-120.

Jаковs, Günther (2000). “¿Existe un aborto lícito de personas?” (trad. González Rivero), Revista del Poder Judicial 60, 2000, pp. 159-168. Grijley. (1998). La imputación objetiva en Derecho penal, Lima:

KINDHÄUSER, Urs (2004). "Imputación objetiva y subjetiva en el delito doloso" (trad. Pastor Muñoz), Cuestiones actuales de Derecho penal 
general y patrimonial, I Jornada de Derecho penal, Facultad de Derecho de la Universidad de Piura, pp. 55-71.

Künsemüller Loebenfelder, Carlos (1986). "Responsabilidad penal del acto médico", en Revista Chilena de Derecho, vol. 13, pp. 93-105.

Labatut Glena, Gustavo (2007). Derecho Penal, t. II, $7^{\mathrm{a}}$ ed., Santiago, Edit. Jurídica de Chile, reimpr.

Lyon Puelma, Alberto (2007). Persona naturales, 3a ed., Santiago, Universidad Católica de Chile.

Manríquez Bustos, Edmundo (1963). Protección penal de la vida humana en su primera etapa, Santiago, Edit. Jurídica de Chile.

Martínez-Buján Pérez, Carlos (2007). Derecho penal económico y de la empresa. Parte general, 2a ed., Valencia, Tirant lo Blanch.

Mayer Lux, Laura (2011). "La vida del que está por nacer como objeto de protección penal", en Revista de Derechos Humanos, Universidad Viña del Mar, No 5, pp. 63-80.

Mir Puig, Santiago (2004). Derecho penal. Parte general, $7^{\text {a }}$ ed., Montevideo-Buenos Aires, Bdef.

Miranda Montecinos, Alejandro (2008). "El principio del doble efecto y su relevancia en el razonamiento jurídico", Revista chilena de Derecho, vol. 35, No 3, pp. 485-519.

Mohor Abuauad, Salvador (1990). "Reflexiones en torno a la prohibición del aborto en Chile", XX Jornadas Chilenas de Derecho Público, II, Valparaíso: Edeval.

(1988). "Consideraciones jurídicas y metajurídicas en torno a una eventual despenalización del aborto en Chile a la luz de la nueva Constitución", Revista de Legislación y Documentación en Derecho, BCN, Año X, No 1, pp. 17-82.

Molina Guaita, Hernán (2011). Derecho constitucional, $11^{\text {a }}$ ed., Santiago: Abeledo Perrot.

Nogueira Alcalá, Humberto (1997). "El derecho a la vida en el ordenamiento jurídico chileno", Gaceta Jurídica, No 207, pp. 7-29.

(2007). Derechos fundamentales y garantias constitucionales, t. I, Santiago: Librotecnia.

Novoa Monreal, Eduardo (2005). Curso de Derecho penal chileno. Parte general, I, $3^{\text {a }}$ ed., Santiago, Edit. Jurídica de Chile, reimpr.

NúNez Leiva, José Ignacio (2010). "Estatuto constitucional del embrión humano", Hemiciclo. Revista de Estudios Parlamentarios, Academia Parlamentaria de la Cámara de Diputados, No 2, pp. 67-86.

Núñez Poblete, Manuel (1997). "El derecho a la vida o el deber de respetar la vida”, en García-Huidobro, J. / Martínez Estay, I. / Núñez Poblete, M.: Lecciones de Derechos Humanos, Valparaíso: Edeval, pp. 45-94.

(1999). "Titularidad y sujetos pasivos de los derechos fundamentales", Revista de Derecho público, Universidad de Chile, 
vol. 63, actas de las XXXI Jornadas de Derecho Público, t. I, pp. 200-208 n. 66.

Oxman Vilches, Nicolás (2004). "Las figuras penales del delito de aborto", en Revista de Derecho, U. Central, No 6, pp. 231-254.

Parada Guzmán, César (1963). El aborto en nuestra legislación y jurisprudencia, Santiago, Edit. Jurídica de Chile.

Politoff, Sergio / Grisolía, Francisco / Bustos, Juan (2006). Derecho Penal Chileno. Parte Especial, 2a ed., Santiago: Editorial Jurídica Congreso.

Politoff, Sergio / Matus, Jean Pierre / Ramírez, M. Cecilia (2011). Lecciones de Derecho penal chileno, Parte especial, 2a ed., reimpresión, Santiago: Edit. Jurídica de Chile.

(2011). Lecciones de Derecho penal chileno, Parte general, 2a ed., reimpresión, Santiago: Edit. Jurídica de Chile.

Precht Pizarro, Jorge (1992). "Consideraciones ético-jurídicas sobre el aborto terapéutico", Revista Chilena de Derecho, No 19, pp. 509-525.

Ragués i VAllès, Ramón (1999). El dolo y su prueba en el proceso penal, Barcelona: J. M. Bosch Editor.

(2007). La ignorancia deliberada en Derecho penal, Barcelona: Atelier.

Reyes Alvarado, Yesid (2002). "El concepto de imputación objetiva", Derecho penal contemporáneo, No 1, pp. 5-34.

Rodríguez Collao, Luis (1992). "El delito de aborto frente a la Constitución de 1980", Revista de Derecho, PUCV, XIV, pp. 369-387.

(2001). Delitos sexuales, Santiago: Edit. Jurídica de Chile.

Romo Pizarro, Osvaldo (1992). Medicina legal. Elementos de Ciencias forenses, Santiago, Edit. Jurídica de Chile.

Roxin, Claus (1997). Derecho penal. Parte general, I (trad. de la 2a ed. alemana por Luzón Peña, Díaz y García Conlledo, Vicente Remesal), Madrid: Civitas.

Rozas Vial, Fernando (1989). "Problemas jurídicos y morales que plantean la inseminación artificial y la fecundación in vitro", Revista Chilena de Derecho, PUC, vol. 16, No 3, pp. 725-752.

Sanhueza Romero, Juana (1990). "Tratamiento jurídico del aborto terapéutico", Revista de Derecho, U. de Concepción, N 187, pp. 27-33.

Schepeler Raveau (1967). El delito de aborto, Santiago: Edit. Jurídica de Chile.

Silva MacIver, Jaime (1995). "El nasciturus y el derecho a la vida", en Revista de derecho público, U. Chile, No 57/58, pp. 177-198.

Silva SÁnchez, Jesús María (1999). "Sobre las actuaciones en una 'situación de necesidad' que no implican deberes de tolerancia”, en Luzón Peña et al. (dir.): Cuestiones actuales de la teoría del delito, Madrid: McGraw-Hill, pp. 155-184. 
(1999 a). Medicinas alternativas e imprudencia médica, Barcelona: J. M. Bosch Editor.

Soler, Sebastián (1978). Derecho penal argentino, t. III, Buenos Aires: Tea.

Soтo Kloss, Eduardo (1991). "La noción de persona en la Constitución: a propósito del que está por nacer”, Revista de Derecho público, U. Chile, No 50, pp. 137-144.

Taboada R., Paulina (2000). "El derecho a morir con dignidad", en Acta Bioethica, Universidad de Chile, vol. 6 No 1, pp. 89-101.

Thomson, Judith Jarvis (1983). "Una defensa del aborto", en Finnis, John et al.: Debate sobre el aborto. Cinco ensayos de filosofía moral, Madrid: Cátedra, pp. 9-32.

Ugarte Godoy, José Joaquín (2006). "El derecho a la vida y la Constitución”, Revista Chilena de Derecho, PUC, vol. 33, No 3, pp. 509-527.

Urria Hering, Pablo (1993). Fundamentación médico legal del aborto terapéutico, Memoria, Universidad Católica de Valparaíso (inédita).

Varela del Solar, Jorge Luis (1990). "Derechos humanos y aborto", Revista de derecho público, U. Chile, No 47/48, pp.195-218.

Van Weezel de la Cruz, Alex / Hermosilla, Juan Pablo (2009). "Contrapunto: El aborto terapéutico", Revista Chilena de Derecho, vol. 36, No 1, pp. 205-208.

Verdugo, Mario / Pfeffer, Emilio / Nogueira, Humberto (1994). Derecho constitucional, 2a ed., Santiago: Edit. Jurídica de Chile.

Vivanco Martínez, Ángela (2001). "El derecho a la vida y la discusión acerca del concepto de persona humana en el ámbito constitucional", Revista Chilena de Derecho, PUC, vol. 28, No 2, pp. 467-480.

Zapata Larraín, Patricio (1988). "Persona y embrión humano. Nuevos problemas legales y su solución en el derecho chileno", Revista Chilena de Derecho, vol. 15, pp. 375-391. 